(๑) Entomologica Fennica. 8.XI.1991

\title{
The genus Prosciara Frey (Diptera, Sciaridae)
}

\author{
Heikki Hippa \& Pekka Vilkamaa
}

Hippa, H. \& Vilkamaa, P. 1991: The genus Prosciara Frey (Diptera, Sciaridae). — Entomol. Fennica 2:113-155.

The concept of Phytosciara Frey with the subgenera $P$. (Phytosciara), $P$. (Dolichosciara) and P. (Prosciara) is polyphyletic and the subgenera are treated as genera. Prosciara includes 1 Holarctic, 8 Palearctic and 28 Oriental species. The species are keyed and described, including the following new species: P. angustiloba sp. n. (Thailand), P. biceps sp. n. (Burma), P. bifida sp. n. (Burma), P. biloba sp. n. (Burma), P. collina sp. n. (Burma), P. crassidens sp. n. (Burma), P. decamera sp. n. (Burma), P. dolichochaeta sp. n. (Burma), P. duplex sp. n. (Burma), P. ensifera sp. n. (Burma), P. filichaeta sp. n. (Burma, Nepal), P. furcifera sp. n. (Burma), P. gemellata sp. n. (Burma), P. gibbosa sp. n. (Burma), P. glomerata sp. n. (Burma), P. latifurca sp. n. (Burma), P. latilingula sp. n. (Burma), P. megacera sp. n. (Burma), P. megachaeta sp. n. (Burma), P. mima sp. n. (Burma), P. pectinifera sp. n. (Japan), P. pentacanta sp.n. (Nepal), P. pentadactyla sp. n. (Burma), P. plusiochaeta sp.n. (Finland), P. pollex sp. n. (Burma), P. processifera sp. n. (Burma), P. quantula sp. n. (Burma), P. tetrix sp. n. (Burma) and P. triloba sp. n. (Burma). Xenopygina Frey is not a synonym of Prosciara but an independent genus. It includes two species: X. hastata (Johannsen) n. comb. (USA) and X. paradoxa (Frey) (USSR).

Heikki Hippa, Swedish Museum of Natural History, Department of Entomology, Box 50007, S-104 05 Stockholm, Sweden

Pekka Vilkamaa, Zoological Museum, University of Helsinki, P. Rautatiekatu 13, SF-00100 Helsinki, Finland

\section{Introduction}

Prosciara Frey, originally described as a subgenus of Neosciara Pettey, is a small group in which only eight species have been included, all except one Palearctic in distribution. Tuomikoski's (1960) classification according to which Prosciara, with Xenopygina Frey as a synonym, should be a subgenus of Phytosciara Frey, has generally been adopted by subsequent authors.

In material collected in the mountains of northeastern Burma we noticed a few sciarids which by their gonostylar structure resembled the known Palearctic species of Prosciara and finally proved to be congeneric with them. A careful examination of the sciarid material of Burma, consisting of about 1500 individuals, revealed no less than 25 strictly sympatric species of Prosciara. This suggested that the Oriental region was the "home" of Prosciara. The checking of smaller collections from different areas of the region yielded, however, only two additional species and only one probable member of the genus was discovered in the literature. 
Apart with this Oriental material, we checked rather extensive Palearctic and Nearctic collections and smaller collections from the Neotropical area and from South Africa, examined earlier known species of the group insofar as it was possible, and perused the existing literature. As a result one undescribed species from Fennoscandia and one from Japan appeared. One species so far known from the Palearctic region only was found in Alaska and a couple of misplaced Palearctic species were discovered, as well as one from Hawaii. Further, the species described earlier proved to be in need of redescription and the taxonomic concept of Prosciara in need of a revision.

\section{Materials and methods}

Part of the material we studied had been mounted on permanent slides by different persons, and part had been kept in ethanol, or, like most of the material from Burma, was dry and pinned. We mounted the specimens kept in ethanol, as well as the pinned ones, on slides in "Euparal" the latter after treating with $\mathrm{KOH}$. The Burman material as a whole was in poor condition, with antennae, legs or parts of them, or even whole heads being broken off and lost in the specimens studied. Due to pinning, the thorax was in most cases badly damaged and thus did not permit careful study and measurements to be made. For this reason, the size of the thorax as well as any ratios or indices demanding measurements of the thorax have been omitted from the descriptions. Not being aware of methods for recognizing female Sciaridae with any certainty we have identified the males of Prosciara only.

The material is deposited in the following institutions, later referred to by the name of the city only: Zoological Museum, University of Helsinki, Helsinki, Swedish Natural History Museum, Stockholm, Natural History Museum, London, Canadian National Collection of Insects, Ottawa and Cornell University Insect Collection, Ithaca.

The illustrations have been made by the aid of a camera lucida attached to a microscope from specimens mounted on slides. We have endeav- oured to make the drawings of the hypopygium and apex of the front tibia as exact as possible up to the thickness and position of individual setae. In a few cases we have taken the liberty of completing some broken setae on one side that are similar to those on the other side in homological positions, or shown setae cut in the drawings to avoid their marring the clarity of other structures. The microtrichia have been omitted from all illustrations. The verbal description of illustrated structures has been restricted to a minimum.

The morphological terminology used in this paper is mostly generally known and does not deserve any special explanation here. Some terms and ways of measurement are indicated in the following figures: Head, Figs. 3, 5 and 8, Wing, Fig. 12, and Hypopygium, Fig. 4. By megasetae we mean the stout spine-like setae or bristles on the gonostylus which sharply differ from other setosity (see Fig. 4.). The megasetae arise from distinct basal sockets. They are commonly found in a variety of groups of Sciaridae. By apical tooth we mean an apical or subapical claw- or toothlike projection of the gonostylus without a basal socket.

In the phylogenetic discussions we apply the methods and terminology of phylogenetic taxonomy (see e.g. Hennig 1966, Wiley 1981).

\section{The genus Prosciara Frey}

Neosciara (Prosciara) Frey, 1942:32. Typespecies Neosciara porrecta Lengersdorf, 1929 (original designation and monotypy).

\section{Description}

Head dark with palpus and proboscis pale. Interfacetal hairs of eyes long, extending well over the surface of facets. Eye bridge complete, composed of 3-5 rows of facets. Anterior vertex bare or with one to several setae. Prefrons with numerous setae. Clypeus bare or with one to many setae. Proboscis normal, not elongated. Maxillary palp 3-segmented, segments several times longer than wide; segment 1 with 2-9 setae, 
with the sensillae widely scattered on dorsal surface, without a sensory pit. Antennal scapus and pedicel with short ventral setae. Flagellar segments of antenna with short necks, surface of segments from rather smooth to rough, setae shorter than the diameter of segment, length/ width of segment 4 1.40-2.80.

Thorax dark or part of pleura and longitudinal stripes on notum paler. Notum with the acrostichal setae weak, posteriorly often nearly absent, the dorsocentral setae strong and the supra-alar setae of mixed weaker and stronger ones including a row of very strong ones. Scutellar margin with strong setae intermixed with weaker ones especially laterally. Episternum 1 with 5-13 setae. Postpronotum, mediotergite and mesoanepisternum bare. Mesokatepisternum high, subtriangular or slightly trapezoidal.

Wing fumose greyish or brownish. Wing length 1.9-3.9 $\mathrm{mm}$. Width/length of wing 0.35 0.50 . c/w 0.50-0.80. R1 short, R1/R 0.65-1.10. $\mathrm{R} 5$ extending beyond the middle of M1. The fork of M (M1 and M2) nearly symmetrical. bM and $\mathrm{r}-\mathrm{m}$ subequal in length or $\mathrm{r}-\mathrm{m}$ longer. $\mathrm{stCu}$ near the length of bM. C and R (R, R1 and R5) setose, r-m, stM, M1, M2, Cu1 and Cu2 setose or bare, $\mathrm{bM}$ and stCu bare. Halter normal.

Legs pale. Femur 1/metatarsus 1 0.85-1.55. Tibial spurs 1:2:2, the spurs longer than the apical width of tibia, the two spurs of tibia 2 and tibia 3 subequal in size. Tibia 1 and 2 with spinose setae ventrally, usually also laterally and dorsally; tibia 3 with spinose setae on all sides, the dorsals forming a long row. Tibia 1 with a subapical prolateral straight comb-like row of strong setae, the row not separated by a bare area on the proximal side. Claws toothed.

Abdomen dark, normal.

Hypopygium pale, with or without an intercoxal lobe. Gonocoxites short or elongated, without conspicuous modifications. Apical inner edge of gonocoxites ventrally with one long seta. Gonostylus variable in shape, without an apical tooth, with or without apical megasetae, without flagellate setae, with a dorsal mesial lobe bearing four to more than ten megasetae. Tergites 9 and 10 normal, without unusual modifications. Sternite 10 with 1-6 setae on each half. Aedeagus variable in shape, aedeagal apodeme normal, not strikingly asymmetrical.

\section{Diagnostic characters}

A commonly used key character in Sciaridae, viz. the presence of a comblike transverse row of bristly setae subapically on the prolateral side of front tibia combines Prosciara with Scatopsciara Edwards, Bradysia Winnertz, Ctenosciara Tuomikoski, Phytosciara Frey, Lobosciara Steffan and Dolichosciara Tuomikoski. From all these Prosciara differs in having dorsomesially on the gonostylus a characteristic lobe or branch that bears megasetae. Some species of Dolichosciara may have a reminiscent lobe, too, but the lobe goes obliquely across the mesial surface and the megasetae are straight, not curved, as in Prosciara.

There are a few species currently placed in Corynoptera which have an almost perfect comb of setae on the front tibia. From these Prosciara differs in e.g. having more than one seta on the first palpal segment, in the lack of an apical tooth, and in having a dorsal lobe with megasetae on the gonostylus. The genus Phorodonta Coquillett (Sciara nigra Wiedemann), which is often mentioned in connection with Phytosciara, does not have a comb on the front tibia (Steffan 1969).

\section{Classification}

Frey (1942) proposed Prosciara (type-species Neosciara porrecta Lengersdorf) as a monotypic subgenus in his Neosciara Pettey (Sciara coprophila Lintner) and the monotypic Xenopygina (X. paradoxa) as a subgenus in his Bradysia Winnertz (B. angustipennis Winnertz). Tuomikoski (1960) considered Xenopygina as a synonym of Prosciara and made Prosciara one of the three subgenera of Frey's (1942) earlier monotypic genus Phytosciara (Sciara halterata Lengersdorf). As the third subgenus of Phytosciara Tuomikoski (1960) proposed Dolichosciara (Sciara flavipes Meigen), the type species of which had long been considered the only European representantive of Phorodonta Coquillett (Lengersdorf 1930, Frey 1942, 1948).

In addition to the type-species of Prosciara and Xenopygina Tuomikoski (1960) included two other species, Sciara ungulata Winnertz and a 


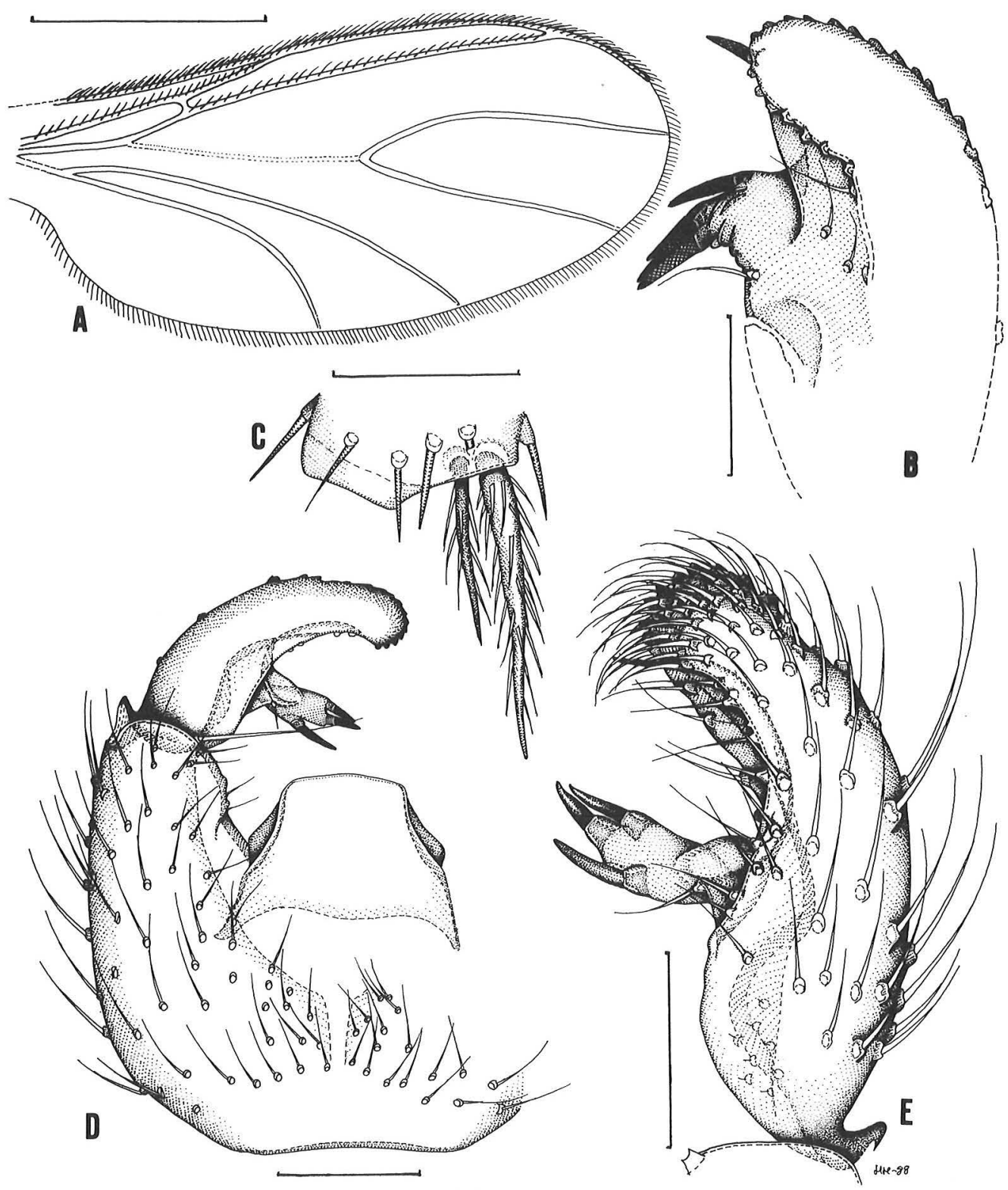

Fig. 1. Wing (A), dorsal view, gonostylus (B and $E$ ) and part of hypopygium (D), ventral view, and apex of hind tibia (C), prolateral view. - A, C, D and E: Xenopygina hastata (Johannsen) (holotype). — B: X. paradoxa (Frey) (holotype). Scale for wing $0.50 \mathrm{~mm}$, for other parts $0.05 \mathrm{~mm}$.

new species P. producta in Prosciara. Tuomikoski (1960) had difficulties in separating Prosciara from Bradysia and with hesitation placed his B. prosciaroides in Bradysia. Tuomikoski's classification of Phytosciara, including the delimitation of Phytosciara (Prosciara) has been generally followed by later authors (Antonova 1977, Freeman 1983, Mohrig, Krivosheina and Mamaev 1985, Steffan 1969, 1972). Antonova (1977) without any argumentation considered Dolichosciara a synonym of Phorodonta but did not use this older name for the genus. 
Antonova (1977) added two new species and also gave a key to the known species of Prosciara. One species, $P$. neofusca was added by Mohrig et al. (1982), but we reject this species from Prosciara, as well as $P$. vulcanata, described by Steffan (1973) from Hawaii. Mohrig and Krivosheina (see Mohrig et al. 1985) described a new species Phytosciara quadriangulata which closely resembles $B$. prosciaroides and expressed their suspicion that both species should be included in Prosciara, with which we agree.

We consider Prosciara a genus because we cannot find anything that could be an autapomorphy of Phytosciara as limited by Tuomikoski (1960). In fact, there are no characters even for the identification of Phytosciara sensu Tuomikoski (1960) and such have not been proposed by anyone, not even by Tuomikoski himself. The same applies to Dolichosciara, which was included by Tuomikoski (1960) as a subgenus in Phytosciara. Instead, the species of Prosciara and Dolichosciara are similar in their general structural pattern and they have a group of dorsal mesial megasetae on the gonostylus which we regard as an apomorphic character state compared to the mesially widely distributed unmodified setosity found on the gonostylus of Phytosciara. There are a number of species currently placed in Bradysia which have a great general resemblance to the species of Prosciara and Dolichosciara and which also have a similar pattern of megasetae on the gonostylus (?synapomorphy). When compared with Bradysia the Prosciara and Dolichosciara differ in having the base of the group of megasetae on the gonostylus prolonged lobe-like, this prolongation possibly being their synapomorphy and Prosciara and Dolichosciara thus being sister groups. Further, the monophyly of both could be argumented as follows: in Prosciara the megasetae on the gonostylus are stout and slightly curved (autapomorphy), while in Dolichosciara they are straight and slender (plesiomorphy). In Dolichosciara the gonocoxites have two or more strong setae at the apicoventral medial angle (autapomorphy) instead of only one in Prosciara (plesiomorphy). We suppose that Bradysia in the current sense is polyphyletic and paraphyletic and that the sister group of Prosciara + Dolichosciara should be searched for among those Bradysia that lack the apical tooth on the gonostylus (apomorphy) and that have the dorsomesial aggregation of megasetae on the gonostylus.

We do not accept the synonymy of Prosciara and Xenopygina proposed by Tuomikoski (1960) on the basis of the similarity between the gonostylus in their type-species. The two species we know to belong to Xenopygina, the Palearctic $X$. paradoxa (Frey, 1942) and the Nearctic X. hastata (Johannsen, 1912), comb. n., are "Bradysialike" species which have on the gonostylus a mesial lobe with megasetae but unlike the species of Prosciara the whole mesial surface of the gonostylus is impressed and the lobe arises from the bottom of this impression. So the lobe is not an outgrowth of the dorsomesial margin of the gonostylus as in the species of Prosciara. We are convinced that the lobes are not homological. The members of Prosciara and Xenopygina are also in many other respects different: the gonocoxites and tegmen which are nearly identical in the both species of Xenopygina (Fig. 1) are of different type in Prosciara (e. g. Figs. 4 and 14), and the wing vein R5 is much shorter (e. g. Figs. 1 and 12). In $X$. hastata the two spurs of middle and hind tibia are conspicuously unequal in length (Fig. 1), not subequal as in the species of Prosciara. Whether $X$. paradoxa is similar is not known because the only known specimen lacks the legs. The spurs of $X$. hastata resemble those of the species of Scatopsciara, except that in that genus one of the spurs of the hind tibia is totally reduced.

\section{Species included}

angustiloba sp. n.: Thailand, p. 134

biceps sp. n.: Burma, p. 152

bifida sp. n.: Burma, p. 128

biloba sp. n.: Burma, p. 150

collina sp. n.: Burma, p. 132

crassidens sp. n.: Burma, p. 128

decamera sp. n.: Burma, p. 146

dolichochaeta sp. n.: Burma, p. 144

duplex sp. n.: Burma, p. 150

ensifera sp. n.: Burma, p. 130

filichaeta sp. n.: Burma, Nepal, p. 145

furcifera sp. n.: Burma, p. 139

gemellata sp. n.: Burma, p. 152

gibbosa sp. n.: Burma, p. 139 
glomerata sp. n.: Burma, p. 130

latifurca sp. n.: Burma, p. 142

latilingula sp. n.: Burma, p. 125

lobata Antonova (Phytosciara): USSR: Primorye, p. 130

megacera sp. n.: Burma, p. 146

megachaeta sp. n.: Burma, p. 135

mima sp. n.: Burma, p. 128

pectinifera sp. n.: Japan, p. 139

pentacanta sp. n.: Nepal, p. 132

pentadactyla sp. n.: Burma, p. 132

plusiochaeta sp. n.: Finland, p. 120

pollex sp. n.: Burma, p. 144

porrecta Lengersdorf (Sciara): W Europe, p. 136

processifera sp. n.: Burma, p. 140

producta Tuomikoski (Phytosciara): Finland, p. 123

prosciaroides Tuomikoski (Bradysia): Finland,

Britain, Austria, USSR:Tuva, USA: Alaska,

p. 120

quadriangulata Mohrig \& Krivosheina (Phyto-

sciara): USSR: Amur Region, p. 123

quantula sp. n.: Burma, p. 125

tetrix sp. n.: Burma, p. 146

triloba sp. n.: Burma, p. 152

ungulata Winnertz (Sciara): Europe, p. 123

ussuriensis Antonova (Phytosciara): USSR:

Primorye, p. 130

Possibly also the following species which we have not seen belongs to Prosciara:

\section{flavipleura Brunetti (Sciara): India}

In addition, Steffan (1981) mentioned an unidentified species of Phytosciara (Prosciara) from Ontario, Canada.

\section{Key to the species of Prosciara}

Because the characters of the wing of $P$. crassidens are not known this species is included in both couplets 2 and 17. Sciara flavipleura which we have not seen is omitted.

1. M1, M2 and Cu1 setose (Figs. 5B, 12A, 12D) ........ 2

- M1, M2 and Cu1 nonsetose (Figs. 3A, 12B) ......... 17

2. The dorsal lobe of gonostylus subapical, in ventral aspect the gonostylus does not appear deeply bilobed (Figs. 4B, 4D, 5C) .....

- The dorsal lobe of gonostylus well basal from apex, in ventral aspect gonostylus appears deeply bilobed (Figs. 10D, 19B, 20B)
3. Gonostylus short and thick, its mesial side basal from the dorsal lobe lengthwise hollowed or impressed (Figs. $4 \mathrm{~B}, 4 \mathrm{D}, 5 \mathrm{C}, 5 \mathrm{G})$

- Gonostylus elongated, its mesial side basal from the dorsal lobe not hollowed or impressed (Figs. 6B, 6D, 7B, 7D)

4. Cu2 with numerous setae (Fig. 5B), gonostylus relatively narrow in ventral aspect (Fig. 5C) ........................ P. producta (Tuomikoski), p. 123

- Cu2 nonsetose or with a few setae only, gonostylus relatively broad in ventral aspect (Figs. 4B, 4D, 5G) .

5. The intercoxal lobe of hypopygium narrow with more or less distinctly notched apex (Figs. 4A, 4C, 4E), the dorsal lobe of gonostylus with five megasetae (Figs. 4B, 4D) .................... P. ungulata (Winnertz), p. 123

- The intercoxal lobe of hypopygium broad and apically rounded (Fig. 5F), the dorsal lobe of gonostylus with four megasetae (Fig. 5G) .. P. latilingula sp. n., p. 125

6. In ventral aspect the apex of the dorsal lobe of gonostylus extends distally as far as the apex of gonostylus (Fig. 6D) ........................ P. crassidens sp. n., p. 128

- In ventral aspect the apex of the dorsal lobe of gonostylus does not extend distally as far as the apex of gonostylus (Figs. 6B, 7B, 7D)

7. The intercoxal lobe of hypopygium deeply emarginated apically, tegmen nearly parallel-sided (Fig. 7A) P. bifida sp. n., p. 128

- The intercoxal lobe of hypopygium not emarginated apically, tegmen narrowing towards apex (Figs. 6A, 7C, 7E) .

8. The intercoxal lobe of gonostylus large, its setae short, much shorter than the width of the lobe (Fig. 7E) ...... P. mima sp. n., p. 128

- The intercoxal lobe of hypopygium small, its setae as long or longer than the width of the lobe (Fig. 6A) .... P. quantula sp. n., p. 125

9. The dorsal lobe of gonostylus subbasal, its megasetae slender (Fig. 20), Cu2 setose ... P. filichaeta sp. n., p. 145

- The dorsal lobe of gonostylus on the apical half or near the middle, its megasetae thick (Figs. 9D, 10D), Cu2 bare

10. The intercoxal lobe of hypopygium small, with 4-10 setae, the lobe separated laterally from the base of gonocoxites by a membraneous area (Fig. 10C) P. pentadactyla sp. n., p. 132

- The intercoxal lobe of hypopygium large, with numerous setae, the lobe not separated laterally from the base of gonocoxites by a membraneous area (Figs. 8D, $9 \mathrm{C}, 13 \mathrm{~A}, 13 \mathrm{C})$

11. The dorsal lobe of gonostylus divided into a ventral, more apical, and into a dorsal, more basal part, both with a group of megasetae (Fig. 9D) ..................... 12

- The dorsal lobe of gonostylus not divided into two parts (Figs. 8E, 13B, 13D, 19B)

12. The intercoxal lobe of hypopygium narrow, longer than broad, apically slightly emarginated (Fig. 9C) P. ensifera sp. n., p. 130 
- The intercoxal lobe of hypopygium broad, broader than long, rounded apically ..................................... 13

13. The length of wing $2.1 \mathrm{~mm}, \mathrm{c} / \mathrm{w} 0.50$, the intercoxal lobe of hypopygium in the form of a horse-shoe, apex of halter pale ......... P. ussuriensis (Antonova), p. 130

- The length of wing $2.7 \mathrm{~mm}, \mathrm{c} / \mathrm{w} 0.66$, the intercoxal lobe of hypopygium in the form of a semicircle, apex of halter dark ............... P. lobata (Antonova), p. 130

14. The dorsal lobe of gonostylus on the apical half of gonostylus, its megasetae strong and long, nearly as long as the lobe itself (Figs. 8E, 13D) .................... 15

- The dorsal lobe of gonostylus approximately at the middle of gonostylus, its megasetae not unusually strong, short, much shorter than the lobe itself (Figs. 13B, 19B)

\section{... 16}

15. The dorsal lobe of gonostylus widened at apex, with six megasetae (Fig. 8E) .... P. glomerata sp. n., p. 130

- The dorsal lobe of gonostylus steadily narrowing towards apex, with four megasetae (Fig. 13D)

P. megachaeta sp. n., p. 135

16. The intercoxal lobe of hypopygium long and narrow, tegmen nearly equilateral (Fig. 13A)

P. angustiloba sp. n., p. 134

- The intercoxal lobe of hypopygium short and broad, tegmen tapering towards apex (Fig. 19A) P. pollex sp. n., p. 144

17. Gonostylus with two dorsal lobes, one subapical, the other more basal, both with megasetae at apex (Figs. 25B, 25D) .

- Gonostylus with one dorsal lobe varying from subapical to subbasal in position .

18. In ventral aspect the two dorsal lobes of gonostylus separated from each other by a gap which at least equals the apical width of the lobes (Fig. 25B) P. triloba sp. n., p. 152

- In ventral aspect the two dorsal lobes of gonostylus close to each other, separated by a narrow gap only and usually overlapping (Fig. 25D) .

P. gemellata sp. n., p. 152

19. The dorsal lobe of gonostylus subapical, in ventral aspect gonostylus does not appear deeply bilobed (Figs. 2B, 2D, 3G, 6D) ... 20

- The dorsal lobe of gonostylus far basal from the apex, in ventral aspect gonostylus appears deeply bilobed (e.g. Figs. 14B, 14E, 15B, 16B, 16D, 17A) .......... 23

20. Gonostylus short and broad, the dorsal lobe of gonostylus short, shorter than its megasetae, the mesial side of gonostylus basal from the dorsal lobe impressed or hollowed (Figs. 2B, 2D, 3G) .

- Gonostylus slender, the dorsal lobe longer than its megasetae, the mesial side of gonostylus basal from the dorsal lobe not impressed (Fig. 6D) .....

P. crassidens sp. n., p. 128

21. Hypopygium without an intercoxal lobe (Figs. $2 \mathrm{~A}$ 2C) ................ P. prosciaroides (Tuomikoski), p. 120

- Hypopygium with an intercoxal lobe (Fig. 3F) ...... 22

22. Tegmen with a lateral, rounded shoulder-like angle ... .. P. quadriangulata (Mohrig \& Krivosheina), p. 123
— Tegmen laterally evenly curved (Fig. 3F) ..... P. plusiochaeta sp. n., p. 120

23. Apex of gonostylus with one or more megasetae (Figs. 22B, 22E, 23D, 23F, 24B, 24D) ……………….... 24

- Apex of gonostylus without megasetae ................... 28

24. Apex of gonostylus with one megaseta, the dorsal lobe of gonostylus very strong, with one of its megasetae more basal than the others (Figs. 22E, 22F) .....

P. megacera sp. n., p. 146

- Apex of gonostylus with 3-4 megasetae, the dorsal lobe of gonostylus weaker, its megasetae in a tight cluster (Figs. 22B, 23D, 23F, 24B, 24D) ............... 25

25. Apex of gonostylus narrow, as narrow or narrower than apex of the dorsal lobe (Figs. 23D, 24B) ....... 26

- Apex of gonostylus broad, broader than apex of the dorsal lobe

26. The megasetae of gonostylus relatively short, about $3 \mathrm{x}$ longer than basally thick (Fig. 23D), R1/R $0.75-0.80$

..P. biloba sp. n., p. 150

- The megasetae of gonostylus relatively long, about $4 \mathrm{x}$ longer than basally thick (Fig. 24B), R1/R 0.60-0.70

..P. biceps sp. n., p. 152

27. The dorsal lobe of gonostylus nearly rectangular to the long axis of gonostylus, the megasetae of gonostylus short, the intercoxal lobe of hypopygium small (Figs. 23F, 24C, 24D) ..................... P. duplex sp. n., p. 150

- The dorsal lobe of gonostylus strongly oblique to the long axis of gonostylus, the megasetae of gonostylus long (Fig. 22B), the intercoxal lobe of hypopygium large (Fig. 22A) ....................... P. tetrix sp. n., p. 146

28. The megasetae of the dorsal lobe of gonostylus long and slender (Figs. 11B, 19D, 21B, 21E) ................ 29

- The megasetae of the dorsal lobe of gonostylus short and thick (Figs. 9B, 14B, 14E, 15B, 16D, 17A) .... 31

29. The dorsal lobe of gonostylus with 5-6 megasetae .. 30

- The dorsal lobe of gonostylus with more than 10 megasetae ........................ P. decamera sp. n., p. 146

30. The distal part of gonostylus, distal from the dorsal lobe, long and slender (Fig. 19D), hypopygium with an intercoxal lobe (Fig. 19C) .. P. dolichochaeta sp. n., p. 144

- The distal part of gonostylus, distal from the dorsal lobe, broad (Fig. 11B), hypopygium without an intercoxal lobe (Fig. 11A) ...... P. pentacanta sp. n., p. 132

31. Hypopygium with a small intercoxal lobe, in ventral view the width of gonostylus similar subapically and at the middle (Figs. 9A, 9B), the front tibia with a comb of six setae .................. P. collina sp. n., p. 132

- Hypopygium without an intercoxal lobe, in ventral view the width of gonostylus subapically much smaller than at the middle (Figs. 14B, 14E, 15B, 16B, 16D, $17 \mathrm{~A}$ ), the front tibial comb with eight or more setae (Figs. 18B, 18D)

32. The dorsal lobe of gonostylus strongly inflattened basoventrally (Figs. 14B, 14E), tegmen with an apicosubapicolateral tooth (Figs. 14A, 14D) ................... 33

- The dorsal lobe of gonostylus not inflattened basoventrally (Figs. 15B, 16B, 16D, 17A), tegmen not toothed (Figs. 15A, 16A, 16C, 17B) ...................... 34 
33. Tegmen strongly tapering towards apex, almost triangular in ventral view (Fig. 14A)

P. porrecta (Lengersdorf), p. 136

- Tegmen almost equilateral in ventral view (Fig. 14D) P. gibbosa sp. n., p. 139

34. The dorsal lobe of gonostylus with 4-5 megasetae in a row (Fig. 15B) P. pectinifera sp. n., p. 139

- The dorsal lobe of gonostylus with 6 or more megasetae in a group.

35. Setae of gonocoxites strong, the ventral membraneous area between gonocoxites with a couple of strong setae (Fig. 16A) ................. P. furcifera sp. n., p. 139

- Setae of gonocoxites weak, the ventral membraneous area between gonocoxites with a few to many fine setae (Figs. 16C, 17B) ...

36. The dorsal lobe of gonostylus broad, rather abruptly tapering at apex (Fig. 16D), wing length 3.2-3.4 mm $P$. latifurca sp. n., p. 142

- The dorsal lobe of gonostylus narrow, gradually tapering towards apex (Fig. 17A), wing length 2.7-3.0 mm P. processifera $\mathrm{sp}$. n., p. 140

\section{The species of Prosciara}

\section{Prosciara prosciaroides (Tuomikoski)}

Bradysia prosciaroides Tuomikoski 1960:113.

Material studied: Lectotype male (here designated): Finland, Vihti, Vihtijärvi, 18.6.1958, R. Tuomikoski (in Helsinki). Paralectotype ơ: Finland, Kuusamo, Oulankajoki, 2.7.1958, R. Tuomikoski (in Helsinki).

Other material: Finland, Iivaara, 23.6.1964, R. Tuomikoski, $20^{7} \sigma^{7}$ (in Helsinki); USA, Alaska, $11 \mathrm{mi} \mathrm{S}$ Anderson Jct, Rte 3, mi 270, alder poplar spruce, 23.6.2.8.1984, S. \& J. Peck, $10^{\top}$ (in Helsinki).

\section{Description}

Head: Fig. 3. Eye bridge with 3 rows of facets. Anterior vertex bare. Prefrons with 18-26 setae. Clypeus with 0-3 setae. Palpal segment 1 with 5-9 setae. Length/width of flagellar segment 4 of antenna 2.50-2.70. - Thorax: Unicolorous dark brown. Episternum 1 with 5-8 setae. — Wing: Fig. 3. Wing length $1.9-2.0 \mathrm{~mm}$. Width/length of wing 0.45. c/w 0.60-0.65. R1/R 0.70-0.85. r-m with 0-1 seta, stM bare, $\mathrm{M} 1$ and $\mathrm{M} 2$ bare, $\mathrm{Cu} 1$ bare and $\mathrm{Cu} 2$ bare. - Legs: Femur 1/metatarsus 1 1.40-1.55. Apex of tibia 1, Fig. 3. Length of spur/width of tibia 1 1.45-1.80. Tibia 1 with 0 dorsal, 3-5 ventral, 0 prolateral and 1-3 retrolateral spinose setae. Tibia 2 without dorsal spinose setae. - Abdomen: Sternite
8 with 11-21 setae. - Hypopygium: Fig. 2. Sternite 10 with 1 seta on each half.

\section{Discussion}

Prosciara prosciaroides was originally described on the basis of three syntype males. Of these we have found only the two listed above, one, also from Finland (Lohja), being probably lost. We have designated one of the existing syntypes as the lectotype of the species.

Freeman (1983) recorded $P$. prosciaroides from Britain, and we judge from the illustration of the hypopygium that the identification is correct. Krivosheina \& Morig (1986) mentioned $P$. prosciaroides from Austria, and USSR, Tuva.

$P$. prosciaroides is similar to $P$. plusiochaeta and $P$. quadriangulata. The distinguishing characters are discussed under the latter two.

\section{Prosciara plusiochaeta sp. n.}

Material studied: Holotype male: Finland, Iivaara, 23.6.1964, R. Tuomikoski (in Helsinki).

\section{Description}

Head: Fig. 3. Eye bridge with 2-3 rows of facets. Anterior vertex bare. Prefrons with 9 setae. Clypeus with 4 setae. Palpal segment 1 with 7 setae. Length/width of flagellar segment 4 of antenna 2.70. - Thorax: Unicolorous dark brown. Episternum 1 with 6 setae. - Wing: Wing length $2.1 \mathrm{~mm}$. Width/length of wing 0.45 . c/w 0.70. R1/R 0.90. r-m bare, stM bare, M1 and $\mathrm{M} 2$ bare, $\mathrm{Cu} 1$ bare and $\mathrm{Cu} 2$ bare. - Legs: Femur $1 /$ metatarsus 11.45 . Tibia 1 with a comb of 6 setae. Length of spur/width of tibia 11.75 . Tibia 1 with 0 dorsal, 4 ventral, 0 prolateral and 0 retrolateral spinose setae. Tibia 2 without dorsal spinose setae. - Abdomen: Sternite 8 with 15 setae. - Hypopygium: Fig. 3. Sternite 10 with 1 seta on each half.

\section{Discussion}

$P$. plusiochaeta is similar to $P$. prosciaroides (Tuomikoski) and P. quadriangulata (Mohrig \& Krivosheina). It differs from both by simple tegmen and from $P$. prosciaroides also in having an intercoxal lobe on hypopygium and in having more numerous setae on gonostylus. From $P$. quadriangulata it differs in having five, not four megasetae on the gonostylus. 

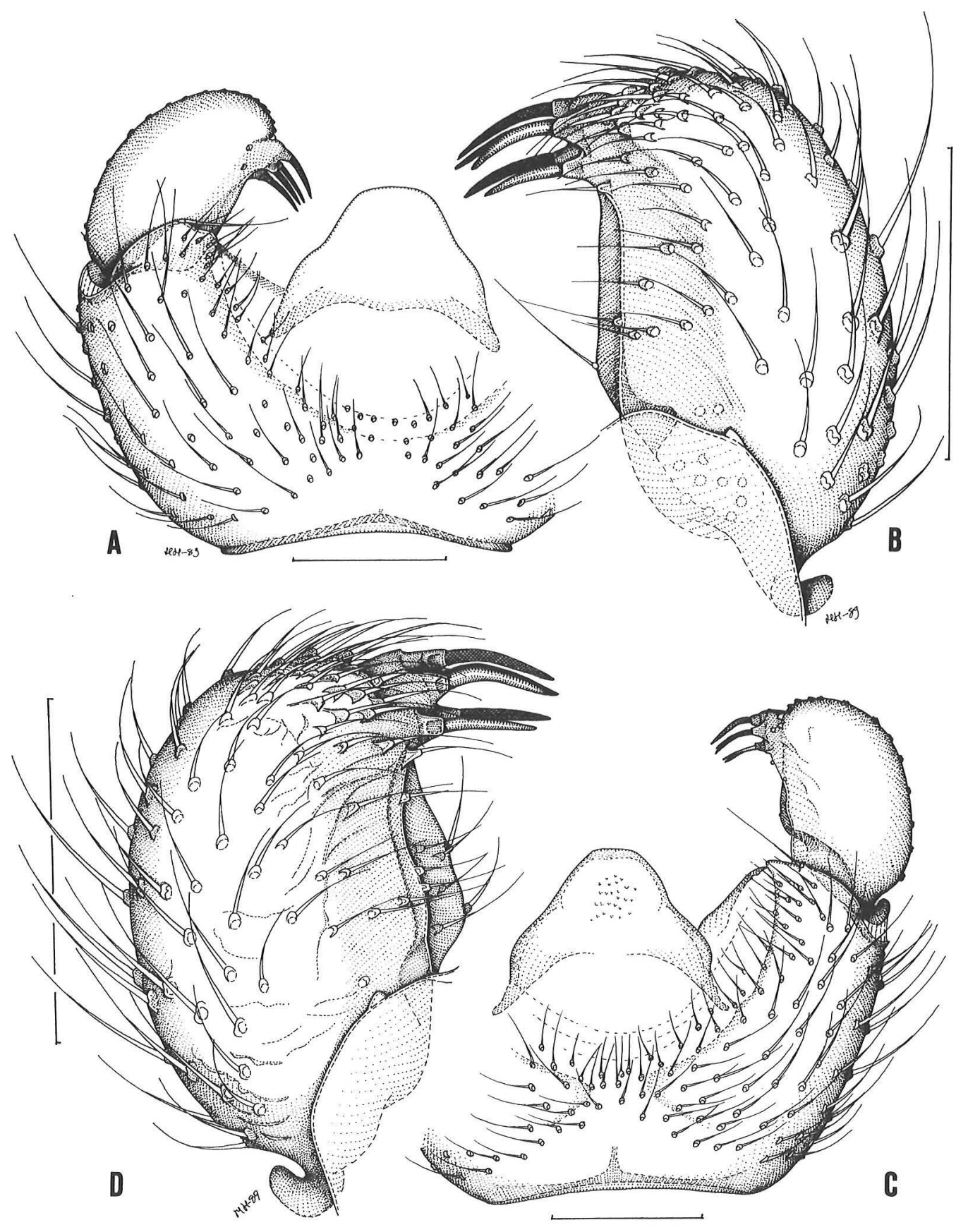

Fig. 2. Prosciara prosciaroides (Tuomikoski) (A and B lectotype, C and D from Alaska): part of hypopygium ( $A$ and $C$ ) and gonostylus (B and D), ventral view. Scale $0.10 \mathrm{~mm}$. 


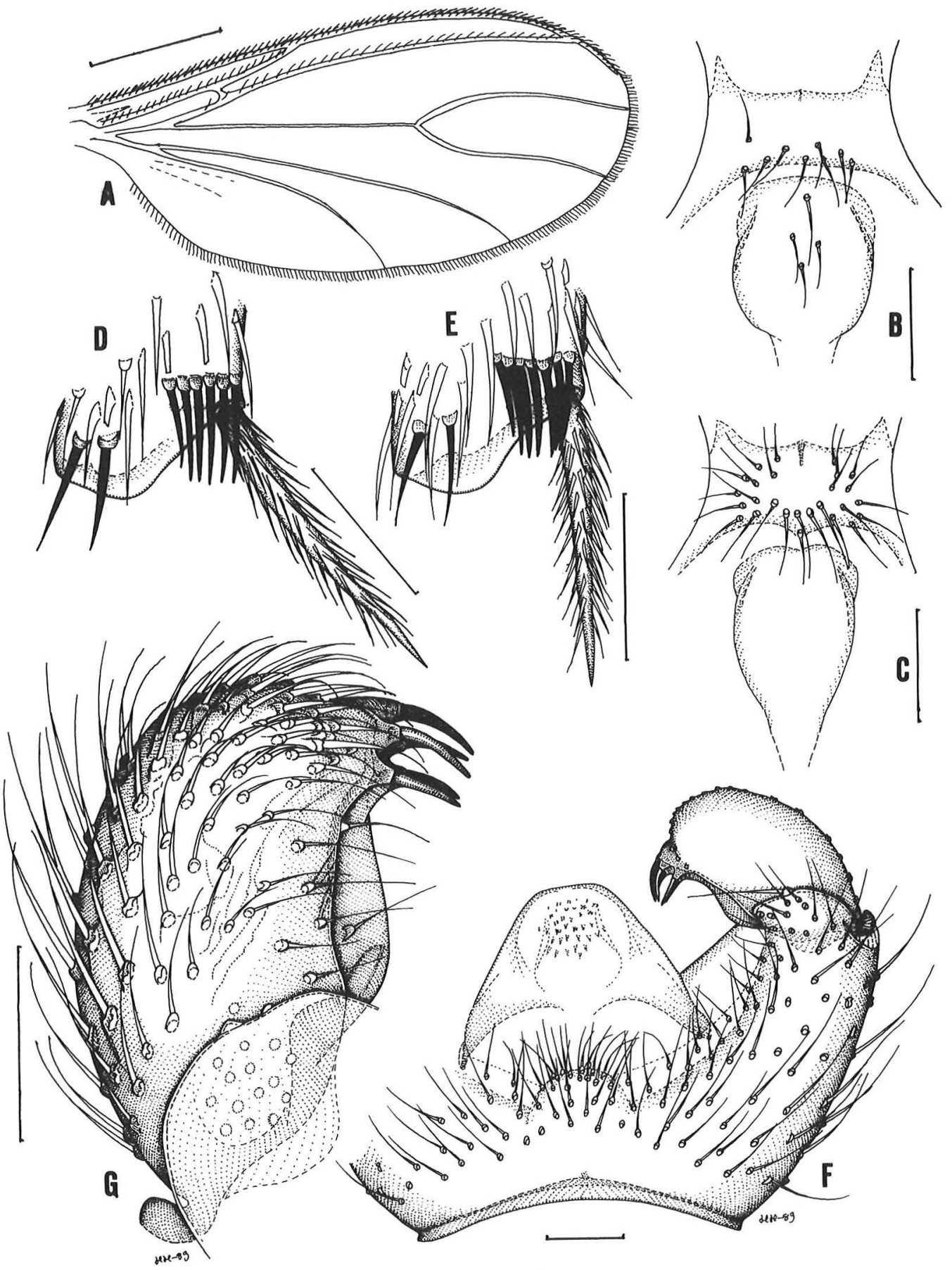

Fig. 3. Wing (A), dorsal view, prefrons and clypeus (B and $C$ ), frontal view, apex of front tibia ( $D$ and $E)$, prolateral view, and part of hypopygium $(\mathrm{F})$ and gonostylus $(\mathrm{G})$, ventral view. $\mathrm{A}, \mathrm{C}$ and $\mathrm{E}$ : Prosciara prosciaroides (Tuomikoski) (A and C from Finland, E from Alaska). - B, D, F and G: P. plusiochaeta sp. n. (holotype). Scale for wing $0.50 \mathrm{~mm}$, for other parts $0.05 \mathrm{~mm}$. 

Prosciara quadriangulata (Mohrig \& Krivo-
sheina)

Phytosciara (Prosciara) quadriangulata Mohrig \& Krivosheina 1985:254.

\section{Description}

See Mohrig et al. 1985.

\section{Discussion}

We have not seen any material of $P$. quadriangulata, described on the basis of one male from the Amur region, USSR. As noted by Mohrig \& Krivosheina (1985) the species is similar to $P$. prosciaroides but differs in having an intercoxal lobe on the hypopygium. Judged from their illustration of hypopygium, the tegmen is more modified compared to $P$. prosciaroides, i.e. the lateral "shoulders" are more pronounced. $P$. quadriangulata is also similar to P. plusiochaeta but the latter has the tegmen unmodified. Further, $P$. quadriangulata differs from the two other species mentioned here in having four fairly long megasetae on the gonostylus instead of five shorter ones.

\section{Prosciara ungulata (Winnertz)}

Sciara ungulata Winnertz, 1867:142.

Lycoria ungulata Lengersdorf 1930

Phytosciara (Prosciara) ungulata Tuomikoski 1960

Material studied: Finland, Lammi, Matoniemi, 6.7.1957, R. Tuomikoski, $10^{7}$ (in Helsinki); Finland, Nauvo, Stenskär, 27.7.-Oct. 1976, P. Lehtinen, $130^{7} \sigma^{7}$ (in Helsinki and in Stockholm).

\section{Description}

Head: Fig. 5. Eye bridge with 3 rows of facets. Anterior vertex with $0-2$ setae. Prefrons with 22-26 setae. Clypeus with 3-7 setae. Palpal segment 1 with 3-5 setae. Length/width of flagellar segment 4 of antenna 1.80-2.20. - Thorax: Dark with indistinct pattern of paler dorsal stripes and lateral patches. Episternum 1 with 9-12 setae. Wing: Wing length $2.1-2.4 \mathrm{~mm}$. Width/length of wing $0.45-0.50$. c/w $0.50-0.55$. R1/R 0.85-1.05. r-m with 1-2 setae, stM with a few setae, M1 and M2 with numerous setae, $\mathrm{Cu} 1$ with numerous setae, $\mathrm{Cu} 2$ bare or with a few setae. - Legs: Femur 1/metatarsus 1 1.15-1.25. Apex of tibia 1, Fig. 4. Length of spur/width of tibia 1 1.70-2.0.
Tibia 1 with 0 dorsal, $4-8$ ventral, $0-1$ prolateral and $0-2$ retrolateral spinose setae. Tibia 2 without dorsal spinose setae. - Abdomen: Sternite 8 with 12 setae. - Hypopygium: Fig. 4. Sternite 10 with $2-3$ setae on each half.

\section{Discussion}

The original description of $P$. ungulata (Winnertz, 1867) is not sufficient for reliable identification of the species, and the type material from ?Crefeld is lost. We base our concept of $P$. ungulata on Lengersdorf $(1924,1925,1930)$ who has studied the types and on Tuomikoski (1960). Tuomikoski noted minor differences in the chaetotaxy of wing veins between his single Finnish male and the description of Lengersdorf (1930). In our present material this variation is to be seen in one population.

$P$. ungulata is rather variable in some characters which are often taxonomically important: 1) $\mathrm{Cu} 2$ is usually bare but it may have one to many setae, 2) the intercoxal lobe of hypopygium may or may not have a deep cleft at apex (Fig. 4.) and 3) the apex of gonostylus is usually without a megaseta but may bear one (Fig. 4).

$P$. ungulata can easily be confused with $P$. producta but can be distinguished e.g. by 1) broader gonostylus which in part is due to expansion of the dorsal mesial margin (cf. Figs. 4 and 5),2) narrower and basally less extensively setose intercoxal lobe of hypopygium (Figs. 4 and 5), 3) tegmen of different shape and 4) shorter costa ( $0.50-0.55$ versus 0.75 in $P$. producta). The nonsetose $\mathrm{Cu} 2$ used by Tuomikoski as a diagnostic character does not always distinguish $P$. ungulata from $P$. producta. $P$. ungulata is recorded from Germany, Poland and Roumania (Gerbachevskaja-Pavluchenko 1986), USSR, Amur Region (Krivosheina \& Mohrig 1986) and from Britain (Freeman 1983) but we have not seen any of this material.

\section{Prosciara producta (Tuomikoski)}

Phytosciara (Prosciara) producta Tuomikoski 1960:104.

Material studied: Lectotype male (here designated): Finland, Vihti, Vihtijärvi, 18.6.1958, R. Tuomikoski (in Helsinki). Syntyper ơ: Finland, Vihti, Vihtijärvi, 19.6.1958, R. Tuomikoski (in Helsinki). 


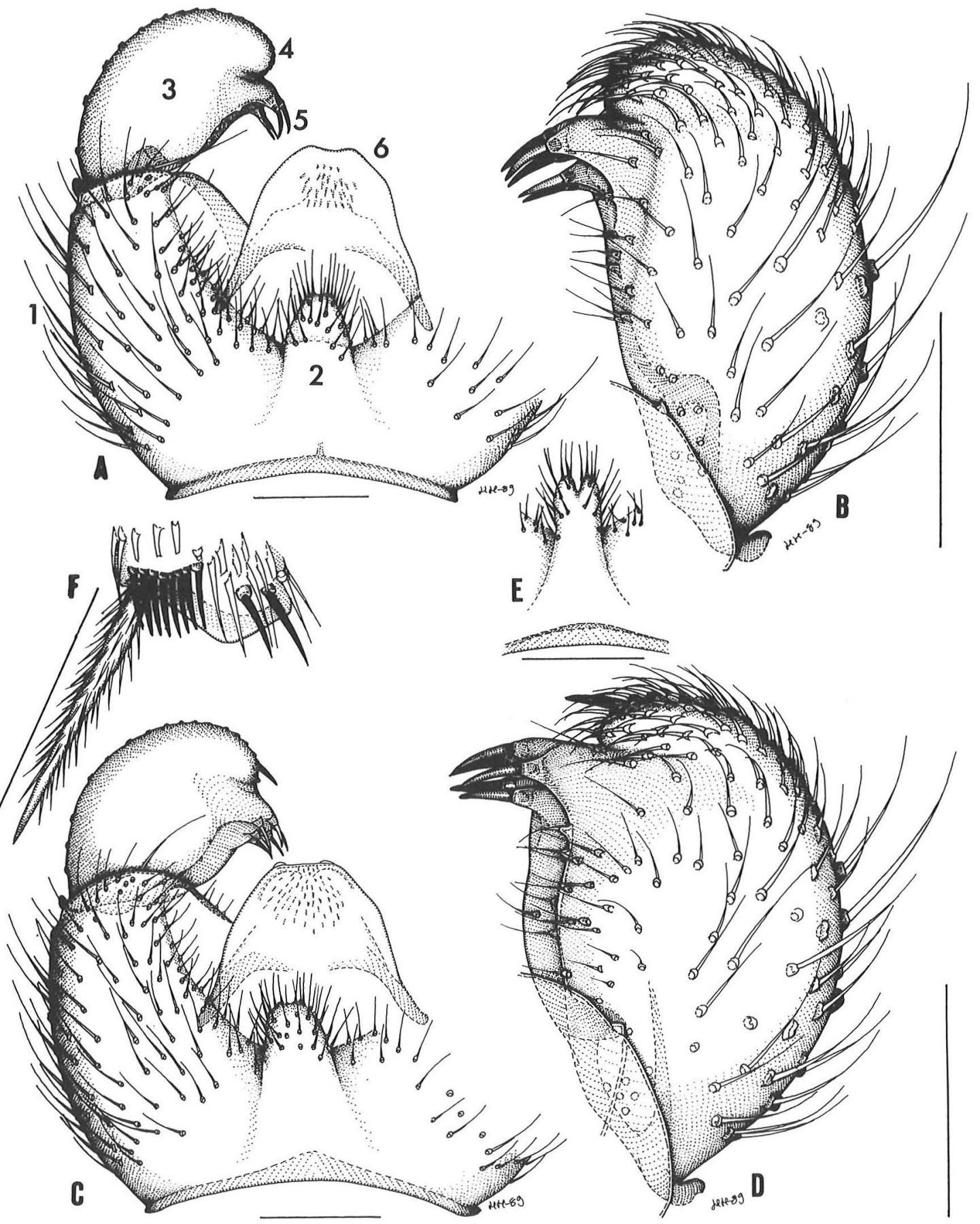

Fig. 4. Prosciara ungulata (Winnertz) (Finland): part of hypopygium ( $A$ and $C$ ), gonostylus $(B$ and $D)$ and the intercoxal lobe of hypopygium $(E)$, ventral view, and apex of front tibia $(F)$, prolateral view. Scale $0.10 \mathrm{~mm}$. 1: gonocoxite, 2: intercoxal lobe of hypopygium, 3: gonostylus, 4: apex of gonostylus, 5: dorsal lobe of gonostylus with megasetae, 6: tegmen. 
Other material: Finland, Koli, 14.6.1964, R. Tuomikoski, $1 \sigma^{7}$ (in Helsinki).

\section{Description}

Head: Eye bridge with 3 rows of facets. Anterior vertex bare. Prefrons with 20-23 setae. Clypeus with 3 setae. Palpal segment 1 with 3-4 setae. Length/width of flagellar segment 4 of antenna 2.25. - Thorax: Unicolorous dark brown. Episternum 1 with $6-9$ setae. - Wing: Fig. 5. Wing length $2.4-2.5 \mathrm{~mm}$. Width/length of wing 0.40-0.45. c/w 0.75. R1/R 0.90-1.00. r-m with $0-1$ seta, stM with a few setae, M1 and M2 with numerous setae, $\mathrm{Cul}$ with numerous setae and $\mathrm{Cu} 2$ with numerous setae. - Legs: Femur 1/ metatarsus 11.25 . Tibia 1 with a comb of 7 setae. Length of spur/width of tibia 1 1.90. Tibia 1 with 0 dorsal, 5 ventral, 0 prolateral and 0 retrolateral spinose setae. Tibia 2 without dorsal spinose setae. - Abdomen: Sternite 8 damaged in both males studied, setae not countable. Hypopygium: Fig. 5. Sternite 10 damaged in both males studied, setae not countable.

\section{Discussion}

The original material of $P$. producta consists of a syntype male and female. Both are probably conspecific as supposed by Tuomikoski (1960), but in order to base the species concept on the male we designate the former as the lectotype.

In addition to the material listed above $P$. producta is recorded from Roumania (Gerbachevskaja-Pavluchenko 1986) but we have not seen that material. For further discussion, see under $P$. ungulata.

\section{Prosciara latilingula sp. n.}

Material studied: Holotype male: N.E. Burma, Kambaiti, 2000 m, 31.3.1934, Malaise (in Stockholm). Paratype ơ: Burma, Kambaiti, 6800 ft, R. Malaise (in Helsinki).

\section{Description}

Head: Eye bridge with 2-3 rows of facets. Anterior vertex with $0-1$ seta. Prefrons with 22 setae. Clypeus with 2 setae. Palpal segment 1 with 2 setae. Length/width of flagellar segment 4 of antenna 2.00. - Thorax: Dark with paler pleura. Epistermum 1 with 8 setae. - Wing: Wing length $2.8-2.9 \mathrm{~mm}$. Width/length of wing 0.45. c/w 0.60-0.70. R1/R 0.90-1.05. r-m with
0-1 seta, stM with numerous setae, M1 and M2 with numerous setae, $\mathrm{Cul}$ with numerous setae and $\mathrm{Cu} 2$ bare. - Legs: Femur 1/metatarsus 1 not measured. Tibia 1 with a comb of 9 setae. Length of spur/width of tibia 1 1.55. Tibia 1 without spinose setae. Tibia 2 without dorsal spinose setae. Abdomen: Sternite 8 with 19 setae. - Hypopygium: Fig. 5. Sternite 10 with 2-3 setae on each half.

\section{Discussion}

$P$. latilingula is similar to the Palearctic $P$. ungulata and $P$. producta in having a short and broad gonostylus in combination with setose $M$ and $\mathrm{Cu} 1$. It differs from both of these species in having a shorter intercoxal lobe of hypopygium, in having broader tegmen and in having the dorsal lobe of the gonostylus less pronounced but with longer megasetae. Further, $P$. latilingula seems to be slightly larger than the two other species (see descriptions).

\section{Prosciara quantula sp. n.}

Material studied: Holotype male: Burma, Kambaiti, $7000 \mathrm{ft}, 1.6 .1934$, R. Malaise (in Stockholm). Paratypes: data as in the holotype, $10^{7}$ (in Stockholm); data as in the holotype but 25.5.1934, $10^{7}$ (in Helsinki) and 12.-17.6.1934, $10^{\top 7}$ (in Helsinki).

\section{Description}

Head: Eye bridge with 3 rows of facets. Anterior vertex with 2-5 setae. Prefrons with 15-29 setae. Clypeus with 2 setae. Palpal segment 1 with 2 setae. Length/width of flagellar segment 4 of antenna 1.60. - Thorax: Original colour not visible in the specimens studied. Episternum 1 with 4-8 setae. - Wing: Wing length 2.5-2.7 $\mathrm{mm}$. Width/length of wing 0.45 . c/w $0.75-0.80$. $\mathrm{R} 1 / \mathrm{R}$ 0.75-0.80. r-m bare, stM bare, M1 and M2 with numerous setae, $\mathrm{Cu} 1$ with numerous setae and $\mathrm{Cu} 2$ bare. - Legs: Femur 1/metatarsus 1 1.00-1.05. Tibia 1 with a comb of 6-7 setae. Length of spur/width of tibia 1 1.70-1.75. Tibia 1 with 0 dorsal, 2 ventral, 0 prolateral and 0 retrolateral spinose setae. Tibia 2 without dorsal spinose setae. - Abdomen: Sternite 8 with 6 setae. - Hypopygium: Fig. 6. Sternite 10 with 1 seta on each half.

\section{Discussion}

In the shape of the gonostylus $P$. quantula resembles $P$. collina. Both differ from other 

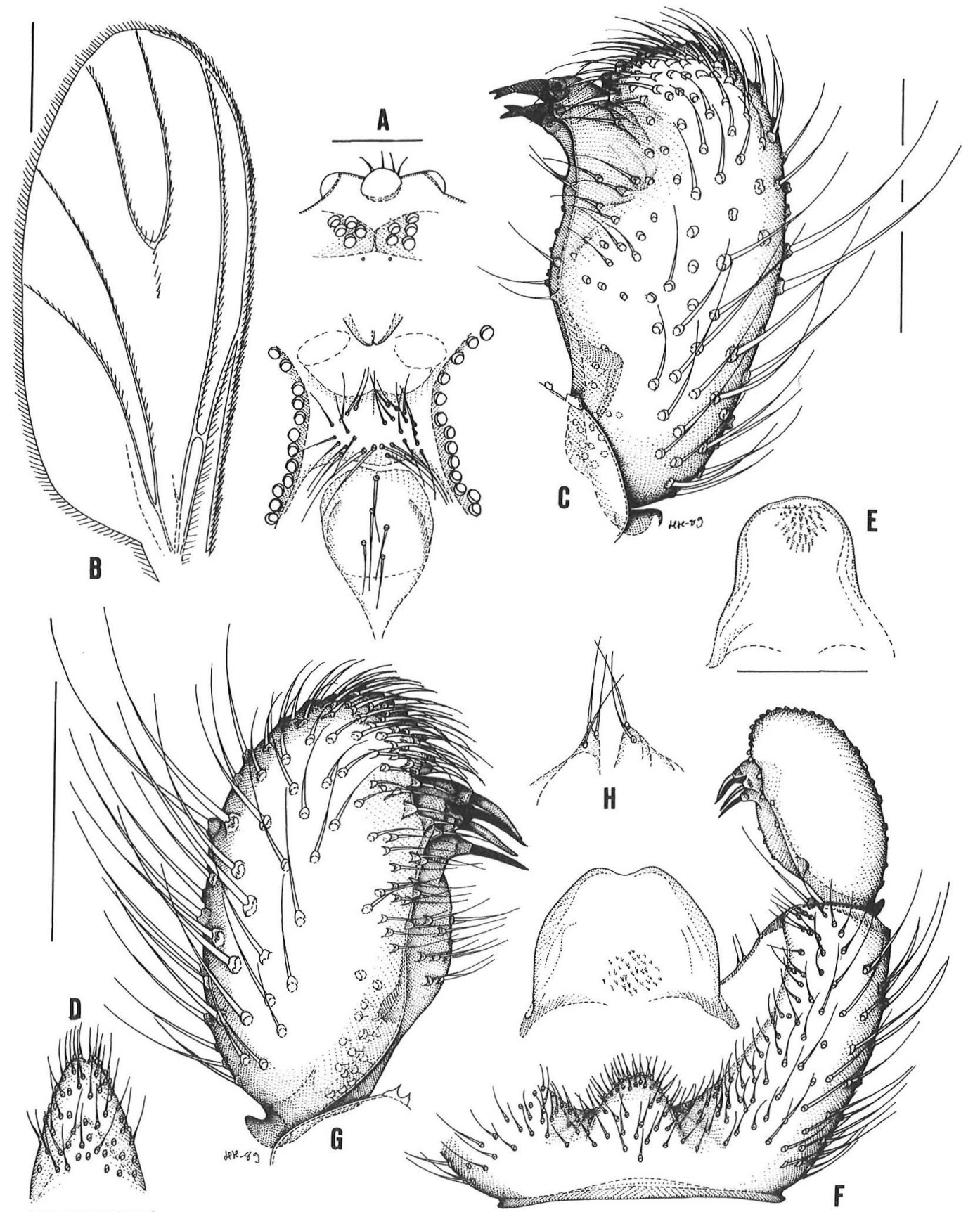

Fig. 5. Medial part of head (A), frontal view, wing (B), dorsal view, and gonostylus ( $C$ and $G$ ), the intercoxal lobe of hypopygium (D), tegmen $(E)$, part of hypopygium $(F)$ and the apical part of sternite $10(H)$, ventral view. $-A$ : Prosciara ungulata (Winnertz) (Finland). - B, C, D, and E: P. producta (Tuomikoski) (lectotype). - F, G and H: $P$. latilingula sp. n. (holotype). Scale for wing $0.50 \mathrm{~mm}$, for other parts $0.10 \mathrm{~mm}$. 

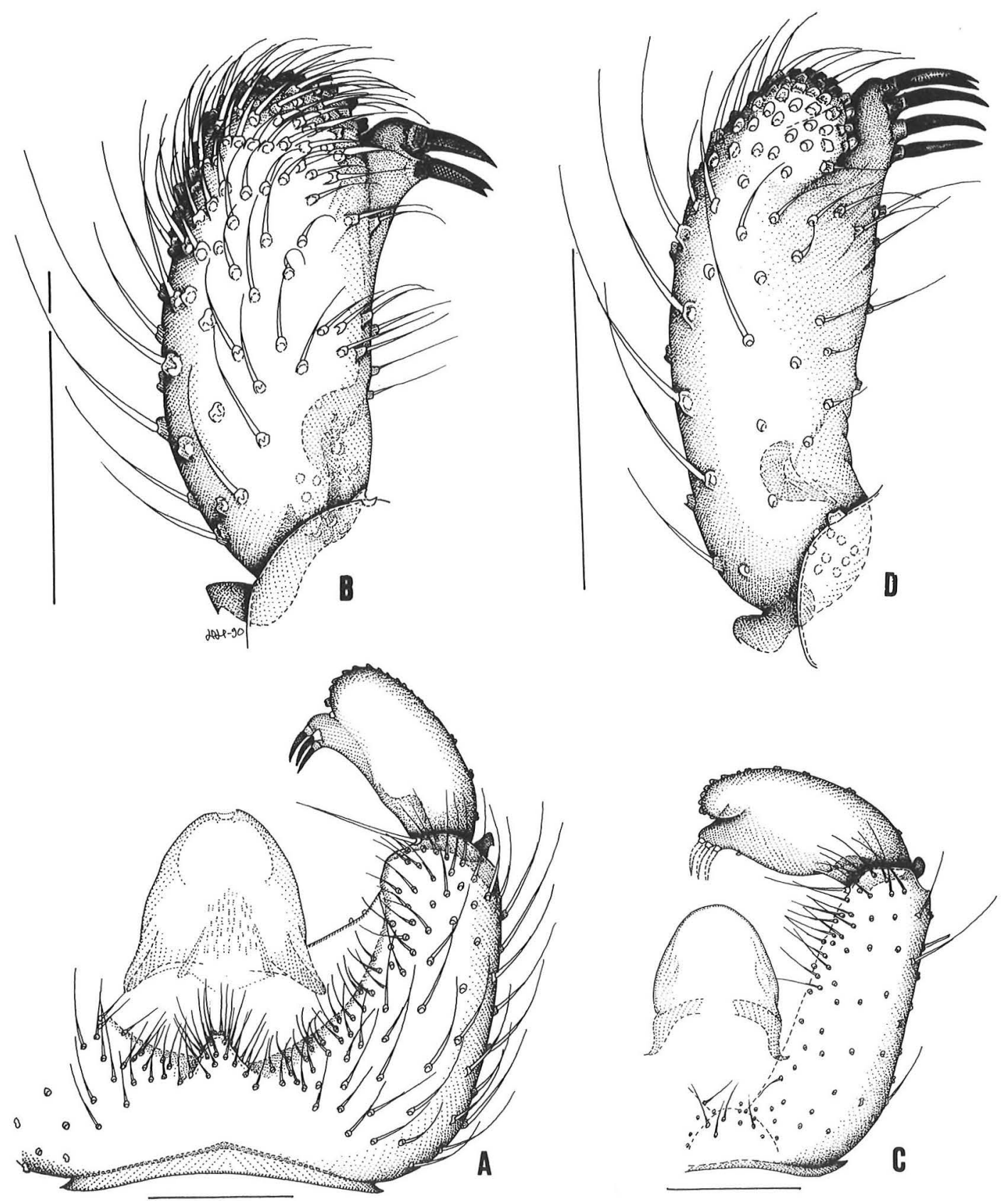

Fig. 6. Part of hypopygium ( $A$ and $C$ ) and gonostylus (B and D), ventral view. - A and B: Prosciara quantula sp. n. (holotype). C and D: P. crassidens sp. n. (holotype). Scale $0.10 \mathrm{~mm}$. 
reminiscent species in having the gonostylus in ventral aspect rather evenly broad. The gonostylus of $P$. quantula differs from that of $P$. collina e.g. by more apical position and by much stronger megasetae of the dorsal lobe. Further, $P$. quantula differs in more prominent intercoxal lobe of hypopygium and in setose, not bare, $\mathrm{M}$ and $\mathrm{Cu} 1$.

\section{Prosciara crassidens sp. n.}

Material studied: Holotype male: Burma, Kambaiti, 7000 ft, 28.5.1934, R. Malaise (in Stockholm).

\section{Description}

Head: Partially damaged in the specimen studied. Prefrons with 30 setae. Clypeus with 2 setae. Antennae lacking in the specimen studied. - Thorax: Damaged in the specimen studied. Abdomen: Sternite 8 damaged in the specimen studied. - Hypopygium: Fig. 6. Sternite 10 damaged in the specimen studied.

\section{Discussion}

Although the only specimen of $P$. crassidens is in poor condition we have described it because the genitalia are very characteristic and easily distinguish the species. In the structure of the gonostylus it resembles $P$. bifida and $P$. mima, but differs from both e. g. in having the dorsal lobe more apical, extending to the level of the apex of the gonostylus, and in having the megasetae in a less compact group. Further, it differs from $P$. bifida in the simple, not bifid, intercoxal lobe of hypopygium and in apicad narrowing arcuate sided, not nearly equilateral tegmen, and from $P$. mima in having five, not four, megasetae on the dorsal lobe of the gonostylus and in having weaker intercoxal lobe of hypopygium with fewer but longer setae.

\section{Prosciara bifida sp. n.}

Material studied: Holotype male: Burma, Kambaiti, $7000 \mathrm{ft}, \mathrm{R}$. Malaise (in Stockholm). Paratype o: data as in the holotype (in Helsinki).

\section{Description}

Head: Eye bridge with 3-4 rows of facets. Anterior vertex bare. Prefrons with 11 setae. Clypeus with 1 seta. Palpal segment 1 damaged in the specimen studied. Length/width of flagellar segment 4 of antenna 1.70. - Thorax: Damaged in the specimen studied. - Wing: Wing length 2.3-2.5 mm. Width/length of wing 0.45 . c/w 0.60-0.75. R1/R 0.85-0.90. r-m bare, stM with a few setae, M1 and M2 with numerous setae, Cul with numerous setae and $\mathrm{Cu} 2$ bare. - Legs: Femur 1/metatarsus 1 not measurable in the specimens studied. Tibia 1 with a comb of 6 setae. Length of spur/width of tibia 1 1.80. Tibia 1 with 0 dorsal, 3 ventral, 0 prolateral and 0 retrolateral spinose setae. Tibia 2 in poor condition in the specimens studied, spinose setae not detectable. - Abdomen: Sternite 8 with 15 setae. - Hypopygium: Fig. 7. Sternite 10 with 1-2 setae on each half.

\section{Discussion}

$P$. bifida is similar to $P$. mima. The species are distinguished e. g. as follows: the dorsal lobe of the gonostylus bears five megasetae in $P$. bifida, four in P. mima, the intercoxal lobe of hypopygium is apically deeply bifid and long setose in P. bifida, apically rounded and very short setose in P. mima and the tegmen is nearly equilateral in $P$. bifida while it has arcuate sides and tapers towards apex in $P$. mima. Both species also resemble $P$. crassidens. For discussion, see under P. crassidens.

\section{Prosciara mima sp. n.}

Material studied: Holotype male: Burma, Kambaiti, $7000 \mathrm{ft}, 12 .-17.6 .1934$, R. Malaise (in Stockholm and in London). Paratypes: data as in the holotype, $30^{7} \sigma^{7}$ (in Stockholm and in London) and Burma, Kambaiti, $7000 \mathrm{ft}$,

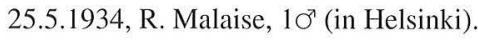

\section{Description}

Head: Eye bridge with 3-4 rows of facets. Anterior vertex bare. Prefrons with 15-25 setae. Clypeus with 0-2 setae. Palpal segment 1 with 2-4 setae. Antennae lacking or in poor condition in the specimens studied. - Thorax: Original colour not visible in the specimens studied. Episternum 1 with 6-7 setae. - Wing: Wing length $2.3-2.4 \mathrm{~mm}$. Width/length of wing 0.450.50. c/w 0.65-0.70. R1/R 0.70-0.75. r-m bare, stM with a few setae, M1 and M2 with numerous setae, $\mathrm{Cu} 1$ with numerous setae and $\mathrm{Cu} 2$ bare. 

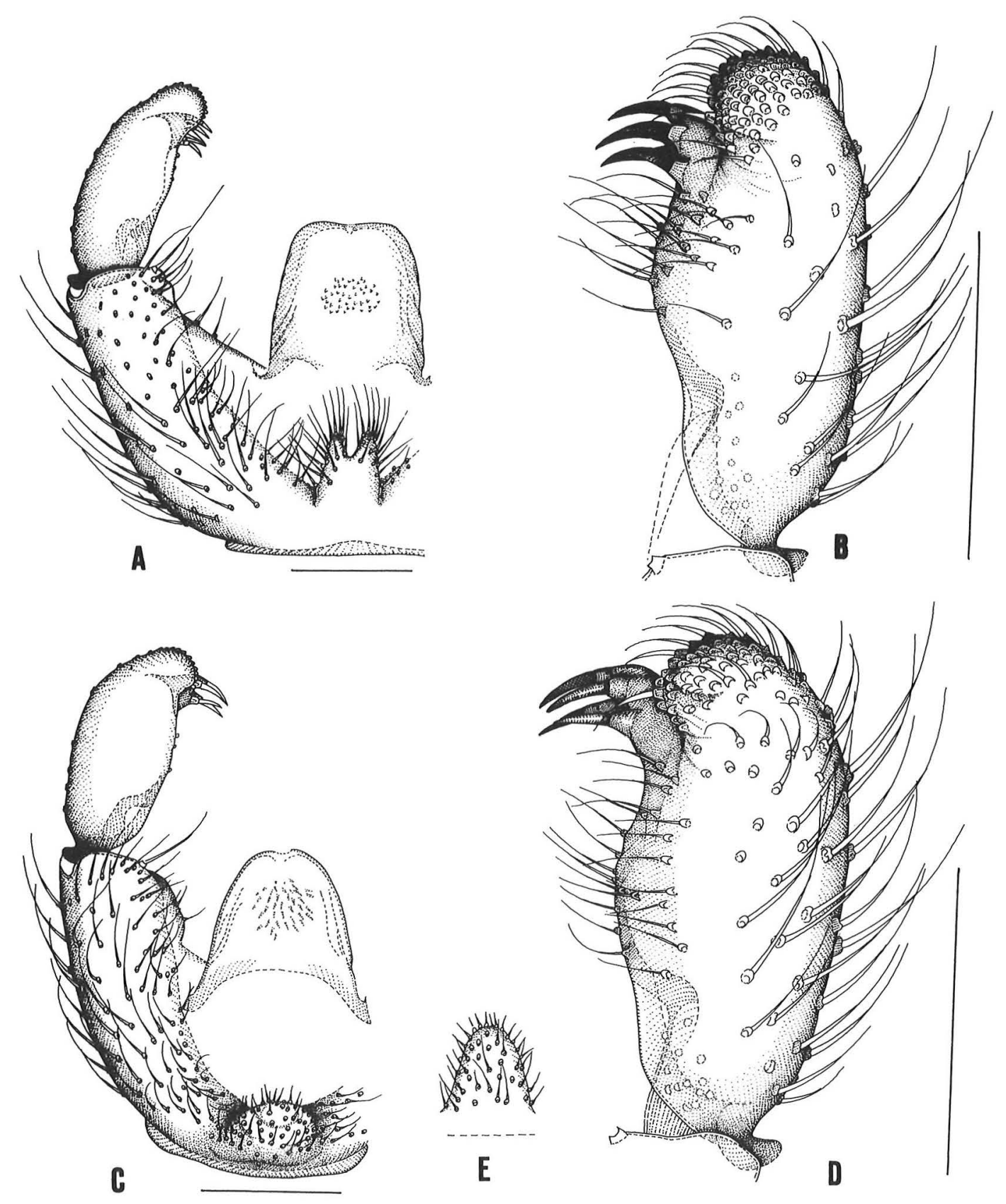

Fig. 7. Part of hypopygium ( $A$ and $C$ ), gonostylus ( $B$ and $D)$ and the intercoxal lobe of hypopygium (E), ventral view. - A and B: Prosciara bifida sp. n. (holotype). - C, D, and E: P. mima sp. n. (holotype). Scale $0.10 \mathrm{~mm}$. 
Legs: Femur 1/metatarsus 1 not measurable in the specimens studied. Tibia 1 with a comb of 57 setae. Length of spur/width of tibia 11.30 1.55. Tibia 1 with 0 dorsal, 2 ventral, 0 prolateral and 0 retrolateral spinose setae. Spinose setae on tibia 2 not detectable in the specimens studied. - Abdomen: Sternite 8 with 15-16 setae. Hypopygium: Fig. 7. Sternite 10 with 1-3 setae on each half.

\section{Discussion}

$P$. mima is similar to $P$. bifida. The distinguishing characters are discussed under the latter.

\section{Prosciara ussuriensis (Antonova)}

Phytosciara (Prosciara) ussuriensis Antonova 1977:110.

\section{Description}

See Antonova 1977.

\section{Discussion}

We have not seen the holotype male from Primorye, USSR, which is the only known specimen. P. ussuriensis is similar to P. lobata from which, according to Antonova (1977), it is distinguished by the characters mentioned in our key. $P$. ussuriensis and $P$. lobata are similar to $P$. ensifera. For discussion, see under the latter. $P$. ussuriensis and $P$. lobata resemble $P$. ungulata, $P$. producta, $P$. latilingula, $P$. prosciaroides, $P$. plusiochaeta and $P$. quadriangulata in having the dorsal lobe of the gonostylus as if bipartite, i.e. divided into a dorsal and ventral part. From all of these species they differ in having the dorsal lobe of hypopygium more basal, situated near the middle of the gonostylus instead of being near to the apex, and in having the general shape of the gonostylus elongated, not tumid.

\section{Prosciara lobata (Antonova)}

Phytosciara (Prosciara) lobata Antonova 1977:112.

\section{Description}

See Antonova 1977.

\section{Discussion}

See under P. ussuriensis.

\section{Prosciara glomerata sp. n.}

Material studied: Holotype male: N.E. Burma, Kambaiti, 2000 m, 7.6.1934, Malaise (in Stockholm).

\section{Description}

Head: Fig. 8. Eye bridge with 3-4 rows of facets. Anterior vertex with 1 seta. Prefrons with 26 setae. Clypeus with 1 seta. Palpal segment 1 with 2 setae. Length/width of flagellar segment 4 of antenna 1.90. - Thorax: Dark with paler pleura. Episternum 1 with 11 setae. - Wing: Tip of wing missing in the specimen studied. R1/R 1.10. r-m with 1 seta, stM bare, M1 and M2 with numerous setae, $\mathrm{Cul}$ with numerous setae and $\mathrm{Cu} 2$ bare. - Legs: Femur 1/metatarsus 1 1.10. Apex of tibia 1, Fig. 8. Length of spur/width of tibia 1 1.80. Tibia 1 with 0 dorsal, 2 ventral, 0 prolateral and 0 retrolateral spinose setae. Tibia 2 without dorsal spinose setae. - Abdomen: Sternite 8 with 19 setae. - Hypopygium: Fig. 8. Sternite 10 with 1 seta on each half.

\section{Discussion}

$P$. glomerata is superficially similar to $P$. ensifera, $P$. ussuriensis and $P$. lobata but differs from these e.g. in having the dorsal lobe of the gonostylus entire, not lengthwise divided into a more dorsal and a more ventral part. This difference may be rather difficult to observe in some preparations. $P$. glomerata differs also from the three mentioned species in having the dorsal lobe widened at the apex.

\section{Prosciara ensifera sp. n.}

Material studied: Holotype male: Burma, Kambaiti, $6800 \mathrm{ft}, 7.4 .1934$, R. Malaise (in Stockholm).

\section{Description}

Head: Eye bridge with 3-4 rows of facets. Anterior vertex bare. Prefrons with 24 setae. Clypeus bare. Palpal segment 1 with ?1 seta. Length/width of flagellar segment 4 of antenna 1.70. - Thorax: Original colour not visible in the specimen studied. Episternum 1 with 8 setae. - Wing: Wing length $2.5 \mathrm{~mm}$. Width/length of wing 0.45 . c/w 0.70 . R1/R $1.00 . \mathrm{r}-\mathrm{m}$ with 2 setae, stM bare, M1 and M2 with numerous setae, $\mathrm{Cu} 1$ with numerous setae and $\mathrm{Cu} 2$ bare. - Legs: Femur 1/metatarsus 1 not measurable 


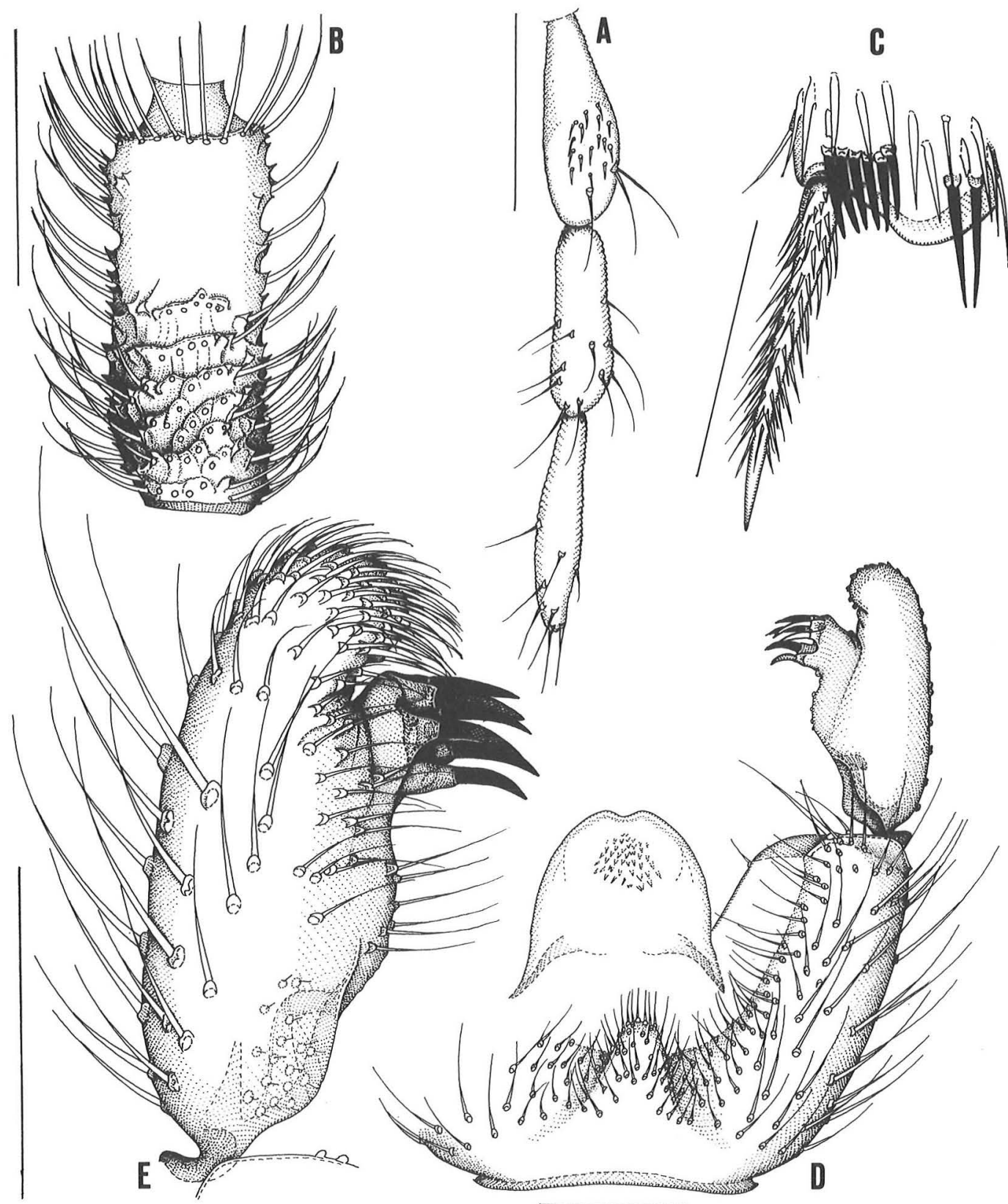

Fig. 8. Maxillary palp (A), dorsal view, flagellar segment 4 of antenna (B), apex of front tibia (C), prolateral view, and part of hypopygium (D) and gonostylus (E), ventral view. - A: Prosciara collina sp. n. (paratype). - B-E: P. glomerata sp. n. (holotype). Scale $0.10 \mathrm{~mm}$.

in the specimen studied. Tibia 1 with a comb of 8 setae. Length of spur/width of tibia 12.2 . Spinose setae of tibia 1 and tibia 2 not detectable in the specimen studied. - Abdomen:
Sternite 8 in poor condition in the specimen studied, setae not countable. - Hypopygium: Fig. 9. Setae on sternite 10 not visible in the specimen studied. 


\section{Discussion}

$P$. ensifera is superficially similar to $P$. glomerata. For distinguishing characters, see under the latter. It is structurally similar to $P$. ussuriensis and $P$. lobata, but differs e.g. in having a long and narrow, not broad and semicircular, intercoxal lobe. For further discussion, see under P. ussuriensis.

\section{Prosciara collina sp. n.}

Material studied: Holotype male: N.E. Burma, Kambaiti, $7000 \mathrm{ft}, 11.5 .1934$, Malaise (in Stockholm). Paratype o?: N.E. Burma, Kambaiti, 2000 m, 6.1934, Malaise (in Helsinki).

\section{Description}

Head: Eye bridge with 3-4 rows of facets. Anterior vertex bare. Prefrons with 15-29 setae. Clypeus with 2-3 setae. Palp, Fig. 8, palpal segment 1 with 4 setae. Length/width of flagellar segment 4 1.90. - Thorax: Dark with paler pleura. Episternum 1 with 9-13 setae. - Wing: Fig. 12. Wing length $2.6 \mathrm{~mm}$. Width/length of wing 0.45 . $\mathrm{c} / \mathrm{w}$ 0.60-0.65. R1/R 0.75. $\mathrm{r}-\mathrm{m}$ bare, stM bare, M1 and M2 with numerous setae, $\mathrm{Cu} 1$ with few setae or bare and $\mathrm{Cu} 2$ bare. - Legs: Femur 1/metatarsus 1 1.20. Apex of tibia 1 with a comb of 6 setae. Length of spur/width of tibia 1 2.25. Tibia 1 with 0 dorsal, ?2 ventral, 0 prolateral and 0 retrolateral spinose setae. Tibia 2 without dorsal spinose setae. - Abdomen: Sternite 8 with 12 setae. - Hypopygium: Fig. 9. Sternite 10 with 2 setae on each half.

\section{Discussion}

$P$. collina with its in ventral aspect nearly evenly broad gonostylus resembles somewhat $P$. quantula. For further discussion, see under the latter. In the placement of the megasetae on the dorsal lobe of the gonostylus $P$. collina somewhat resembles $P$. pentadactyla and $P$. pentacanta but otherwise the species are greatly different.

\section{Prosciara pentadactyla sp. n.}

Material studied: Holotype male: N.E. Burma, Kambaiti, $7000 \mathrm{ft}, 11.5 .1934$, Malaise (in Stockholm). Paratypes: N.E. Burma, Kambaiti, 7000 ft, 11.5.1934, Malaise, $30^{7} \sigma^{7}$ (in Stockholm); N.E. Burma, Kambaiti, 2000 m, 21.5.1934,
Malaise, $10^{7}$ (in Stockholm); N.E. Burma, Kambaiti, 2000 $\mathrm{m}, 4.6 .1934$, Malaise, $50^{7} \sigma^{\top}$ (in Helsinki and in London); N.E. Burma, Kambaiti, 2000 m, 7.6.1934, Malaise, $10^{\top}$ (in Stockholm); N.E. Burma, Kambaiti, 2000 m, Malaise, $10^{7}$ (in Stockholm).

\section{Description}

Head: Fig. 10. Eye bridge with 4-5 rows of facets. Anterior vertex with $2-9$ setae. Prefrons with 18-45 setae. Clypeus with 1-3 setae. Palpal segment 1 with 3 setae. Length/width of flagellar segment 4 of antenna 1.40-1.70. — Thorax: Dark with paler stripes. Episternum 1 with 9-12 setae. - Wing: Fig. 12. Wing length 2.5-3.1 mm. Width/length of wing $0.40-0.45$. c/w $0.65-0.70$. $\mathrm{R} 1 / \mathrm{R}$ 0.85-1.05. r-m with 2-6 setae, stM with a few setae, M1 and M2 with numerous setae, Cu1 with numerous setae and $\mathrm{Cu} 2$ bare. - Legs: Femur 1/metatarsus 1 1.05. Apex of tibia 1, Fig. 10. Length of spur/width of tibia 1 1.80-1.95. Tibia 1 with 0 dorsal, $1-3$ ventral, 0 prolateral and 0 retrolateral spinose setae. Tibia 2 without dorsal spinose setae. - Abdomen: Sternite 8 with 11-16 setae. - Hypopygium: Fig. 10. Sternite 10 with 1-2 setae on each half.

\section{Discussion}

The hypopygium of $P$. pentadactyla bears some resemblance to that of $P$. pentacanta, but has relatively shorter megasetae on the dorsal lobe of the gonostylus. $P$. pentadactyla has also an intercoxal lobe of hypopygium which is absent in $P$. pentacanta. Further, $P$. pentadactyla has setose $\mathrm{M}$ and $\mathrm{Cu} 1$. From all other species of the genus it differs in having the megasetae on the dorsal lobe of the gonostylus directed obliquely ventrad, not mesad as the other species.

\section{Prosciara pentacanta sp. n.}

Material studied: Holotype male: Nepal, Pheol Chuki, $8000 \mathrm{ft}, 17.8 .1967$, Canad. Nepal Exp. (in Ottawa).

\section{Description}

Head: Eye bridge with 3 rows of facets. Anterior vertex bare. Prefrons with 21 setae. Clypeus with 1 seta. Palpal segment 1 with 2 setae. Length/ width of flagellar segment 4 of antenna 1.90. Thorax: Dark with paler pleura. Setae on episternum 1 not visible in the specimen studied. Wing: Wing length $2.7 \mathrm{~mm}$. Width/length of wing 0.40 . c/w $0.60 . \mathrm{R} 1 / \mathrm{R} 0.75$. r-m bare, stM 


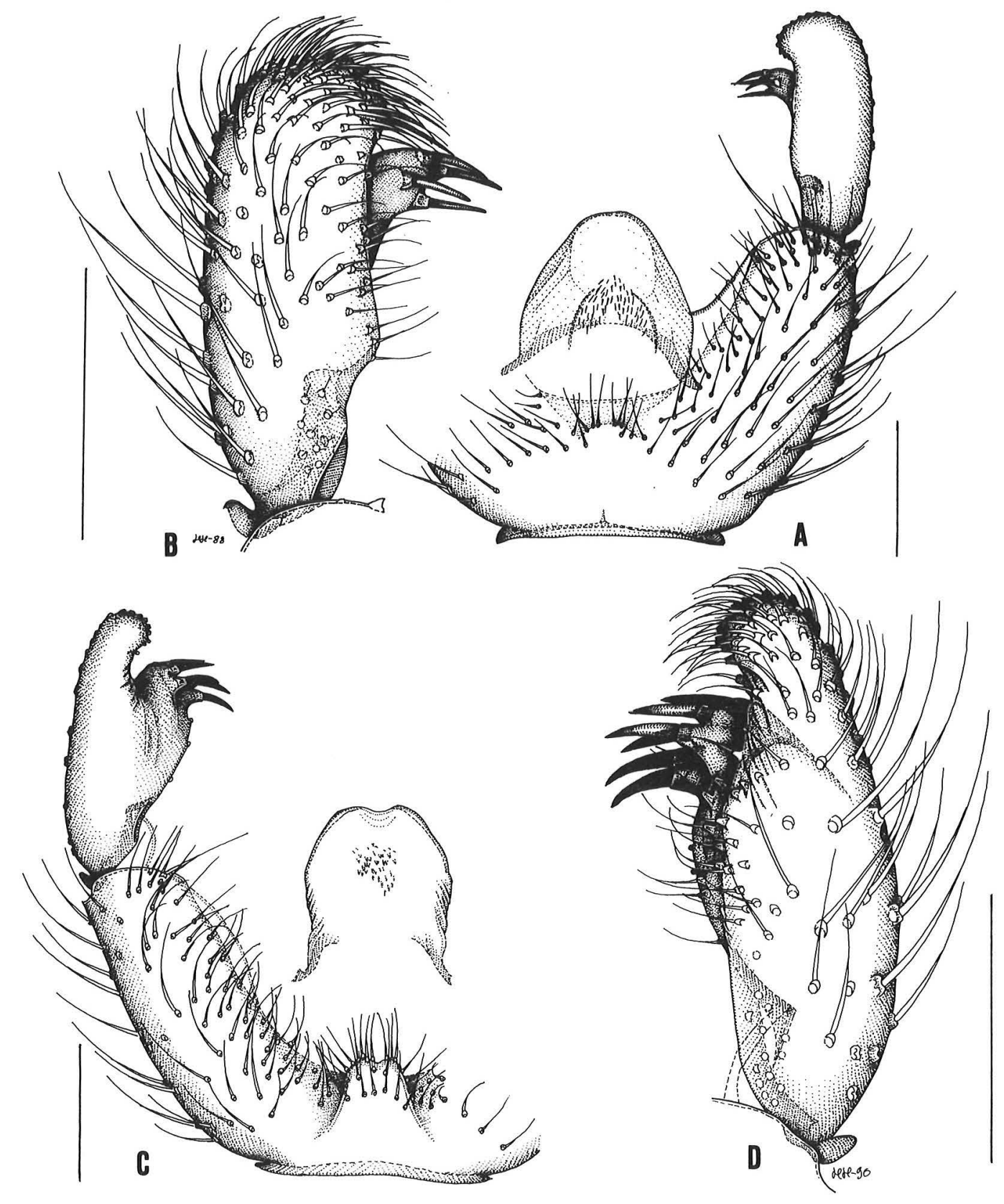

Fig. 9. Part of hypopygium ( $A$ and $C$ ) and gonostylus ( $B$ and $D$ ), ventral view. - A and B: Prosciara collina sp. $n$. (holotype). $-C$ and D: $P$. ensifera sp. n. (holotype). Scale $0.10 \mathrm{~mm}$. 




Fig. 10. Prosciara pentadactyla sp. n. (A and B paratypes, $C$ and $D$ holotype): part of head (A), frontal view, apex of front tibia (B), prolateral view, part of hypopygium (C) and gonostylus (D), ventral view. Scale $0.10 \mathrm{~mm}$.

bare, M1 and M2 bare, Cu1 bare and Cu2 bare. - Legs: Femur 1/metatarsus 1 1.00. Apex of tibia 1 with a comb of 8 setae. Length of spur/ width of tibia 1 1.70. Tibia 1 with 3 dorsal, 0 ventral, 0 prolateral and 2 retrolateral spinose setae. Tibia 2 with 1 dorsal spinose seta. Abdomen: Sternite 8 in poor condition in the specimen studied, setae not visible. Hypopygium: Fig. 11. Sternite 10 with 1 seta on each half.

\section{Discussion}

$P$. pentacanta resembles $P$. pentadactyla. For distinguishing characters, see under the latter.

\section{Prosciara angustiloba sp. $\mathrm{n}$.}

Material studied: Holotype male: Thailand, Phetchabun Pr., Nam Nao N.P., 29.10.-19.11.1976, J. Ruohomäki, E. Huitula \& P. Lehtinen (in Stockholm). 

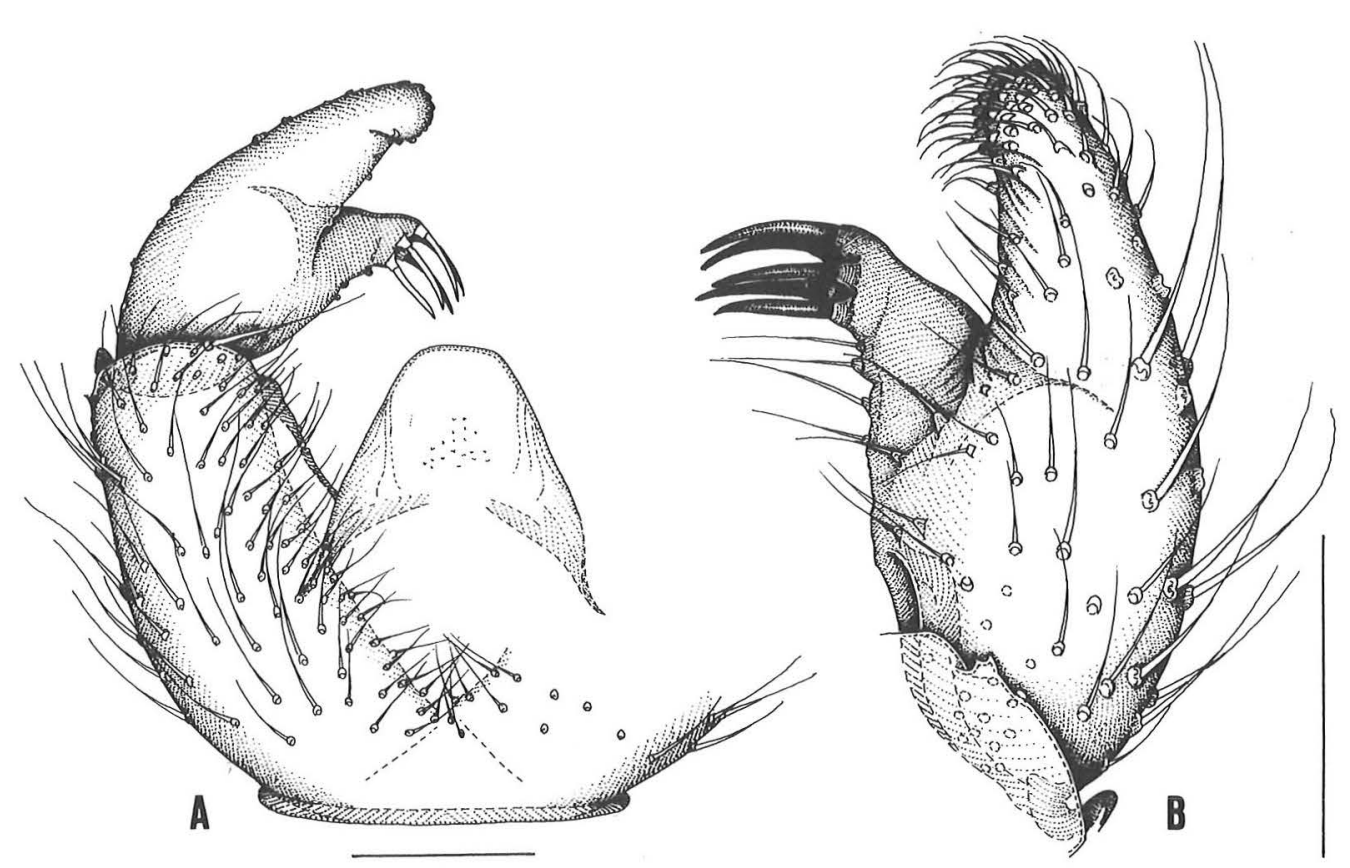

Fig. 11. Prosciara pentacanta sp. n. (holotype): part of hypopygium (A) and gonostylus (B), ventral view. Scale $0.10 \mathrm{~mm}$.

\section{Description}

Head: Eye bridge with 3-4 rows of facets. Anterior vertex bare. Prefrons with 28 setae. Clypeus with 2 setae. Palpal segment 1 with 2 setae. Length/width of flagellar segment 4 of antenna 2.30. - Thorax: Dark brown. Episternum 1 with 7 setae. - Wing: Wing length $2.1 \mathrm{~mm}$. Width/length of wing 0.45 . c/w 0.75 . R1/R 0.85 . $\mathrm{r}-\mathrm{m}$ bare, stM with few setae, M1 and M2 with numerous setae, $\mathrm{Cu} 1$ with numerous setae and $\mathrm{Cu} 2$ bare. - Legs: Legs 1 in poor condition in the specimen studied. Tibia 1 with a comb of 7 setae. Length of spur/width of tibia 1 about 1.50 1.60. Tibia 1 without spinose setae. Tibia 2 without dorsal spinose setae. - Abdomen: Sternite 8 with 16 setae. - Hypopygium: Fig. 13. Sternite 10 with 1 seta on each half.

\section{Discussion}

Our only specimen of $P$. angustiloba has the dorsal lobe of the gonostylus slightly broken on both sides. The number of megasetae on the lobe is at least four. The hypopygium of P. angustiloba somewhat recalls $P$. megachaeta, but is distinguished by a much narrower intercoxal lobe, relatively longer and narrower tegmen, more basal position of the dorsal lobe of the gonostylus and by its shorter and more slender megasetae.

\section{Prosciara megachaeta sp. n.}

Material studied: Holotype male: N.E. Burma, Kambaiti, 2000 m, 4.6.1934, Malaise (in Stockholm).

\section{Description}

Head: Eye bridge with 3-4 rows of facets. Anterior vertex bare. Prefrons with 27 setae. Clypeus with 1 seta. Palpal segment 1 with 2 setae. Length/width of flagellar segment 4 of antenna 1.80. - Thorax: dark with paler pleura. Episternum 1 with 11 setae. - Wing: Fig. 12. Wing length $2.3 \mathrm{~mm}$. Width/length of wing 0.45 . c/w 0.70. R1/R 0.85. r-m with 5 setae, stM with a few setae, M1 and M2 with numerous setae, Cu1 with numerous setae and $\mathrm{Cu} 2$ bare. - Legs: 

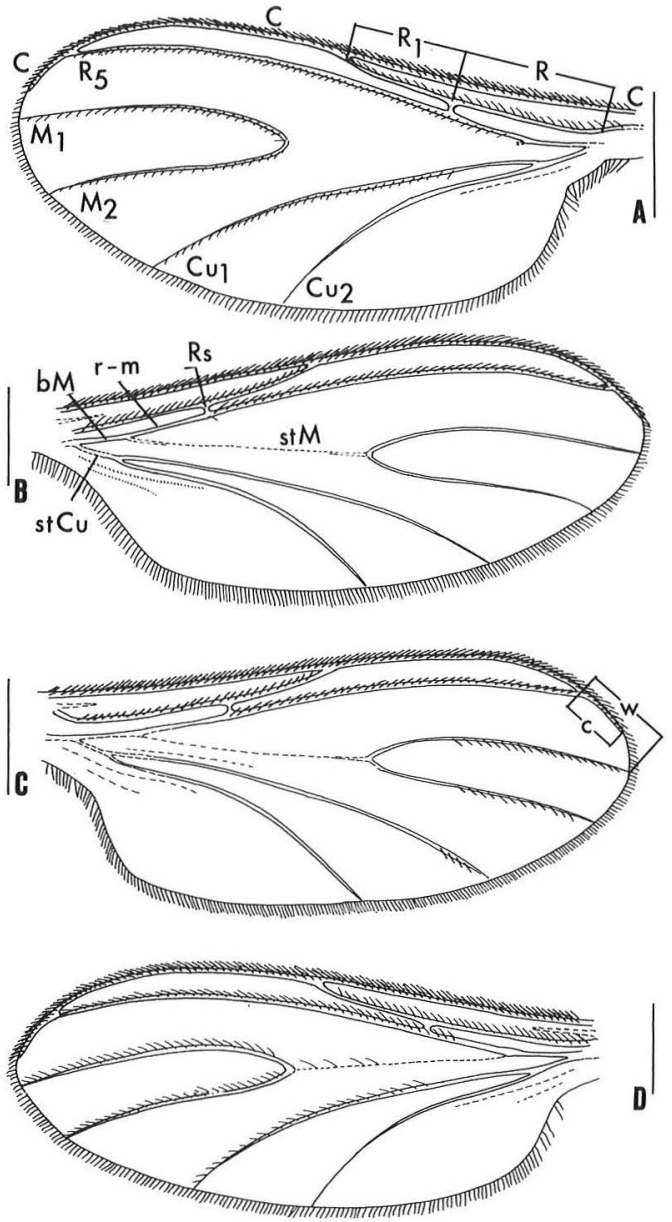

Fig. 12. Wing, dorsal view. - A: Prosciara megachaeta sp. n. (holotype). - B: P. duplex sp. n. (paratype). C: $P$. collina sp. n. (paratype). - D: $P$. pentadactyla sp. n. (paratype). Scale $0.50 \mathrm{~mm}$. bM: base of media, C: costa, c: way of measuring $\mathrm{c}$ for ratio $\mathrm{c} / \mathrm{w}, \mathrm{Cu}$ : cubitus 1, Cu2: cubitus 2, M1: media 1, M2: media 2, $R$ : radius, $R 1$ : radius $1, R 5$ : radius 5 , Rs: radial sector, $r-m$ : radiomedial cross vein, stCu: stem of cubitus, stM: stem of media, w: way of measuring $w$ for ratio $\mathrm{c} / \mathrm{w}$.

Femur 1 broken in the specimen studied. Tibia 1 with a comb of 6 setae. Length of spur/width of tibia 1 1.60. Tibia 1 with 0 dorsal, 3 ventral, 0 prolateral and 0 retrolateral spinose setae. Tibia 2 without dorsal spinose setae. - Abdomen: Sternite 8 with 17 setae. - Hypopygium: Fig. 13. Sternite 10 with 1 seta on each half.

\section{Discussion}

The hypopygium of $P$. megachaeta recalls $P$. angustiloba but differs in the much broader intercoxal lobe, relatively shorter and broader tegmen and more apical position of the dorsal lobe of the gonostylus with much longer and stronger megasetae.

\section{Prosciara porrecta (Lengersdorf)}

Sciara (Neosciara) porrecta Lengersdorf 1929:108. Lycoria (Neosciara) porrecta Lengersdorf 1930 Neosciara porrecta Lackschewitz 1934 Neosciara (Prosciara) porrecta Frey 1942 Phytosciara (Prosciara) porrecta Tuomikoski 1960

Material studied: Finland, Vihti, Vihtijärvi, end of August 1958, R. Tuomikoski, $10^{\top}$ (in Helsinki).

\section{Description}

Head: Eye bridge with 3-4 rows of facets. Anterior vertex bare. Prefrons with 32 setae. Clypeus with 4 setae. Palpal segment 1 with 3 setae. Length/width of flagellar segment 4 of antenna 1.75. - Thorax: Dark brown. Episternum 1 with 13 setae. - Wing: Wing length $3.9 \mathrm{~mm}$. Width/length of wing 0.40. c/w 0.65. R1/R 0.90. r-m with 8-10 setae, stM bare, M1 and M2 bare, $\mathrm{Cu} 1$ bare and $\mathrm{Cu} 2$ bare. - Legs: Femur 1/metatarsus 10.95 . Apex of tibia 1 with a comb of 13 setae. Length of spur/width of tibia 1 1.50. Tibia 1 with 0 dorsal, 2-3 ventral, 0 prolateral and 3 retrolateral spinose setae. Tibia 2 without dorsal spinose setae. - Abdomen: Sternite 8 with 22 setae. - Hypopygium: Fig. 14. Sternite 10 with 6 setae on each half.

\section{Discussion}

The original description was based on a male from Nowy Sacz, Poland. We have not managed to get the holotype for study and we base our concept of the species on the original description, including an illustration of the gonostylus. The single male we have studied is one of Tuomikoski's (1960) two males from Vihti, Finland. The specimen fits the original description rather perfectly, except that the dorsal lobe of the gonostylus, according to Lengersdorf (1929), bears only one megaseta (Dorn). In our specimen the four megasetae on the dorsal lobe of the gonostylus are very closely set in an oblique row that may very easily give an impression of just one megaseta. 

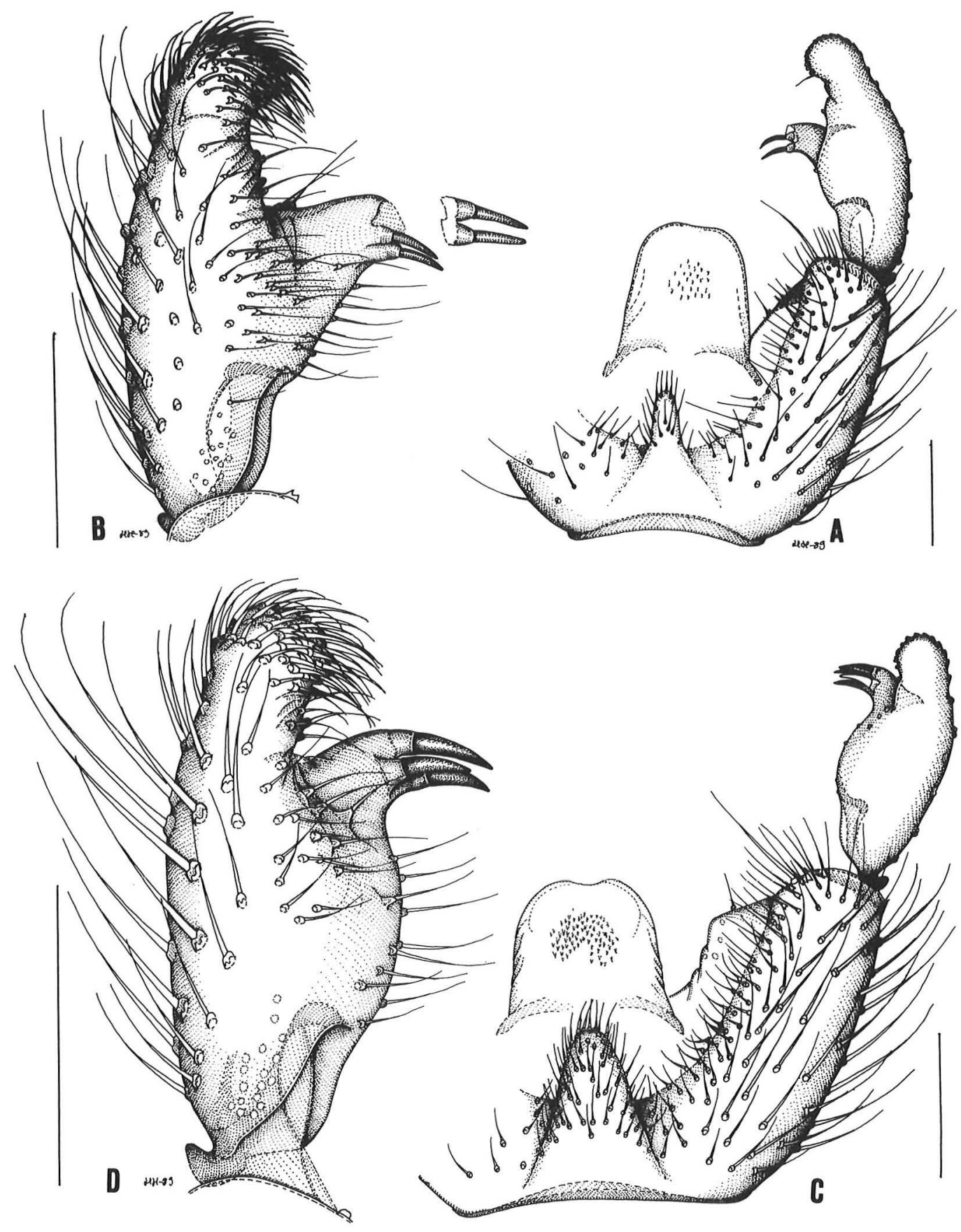

Fig. 13. Part of hypopygium ( $A$ and $C$ ) and gonostylus $(B$ and $D$ ), ventral view, $B$ with the broken apical part of the dorsal lobe inserted near the lobe. - A and B: Prosciara angustiloba sp. n. (holotype). - C and D: P. megachaeta sp. n. (holotype). Scale $0.10 \mathrm{~mm}$. 


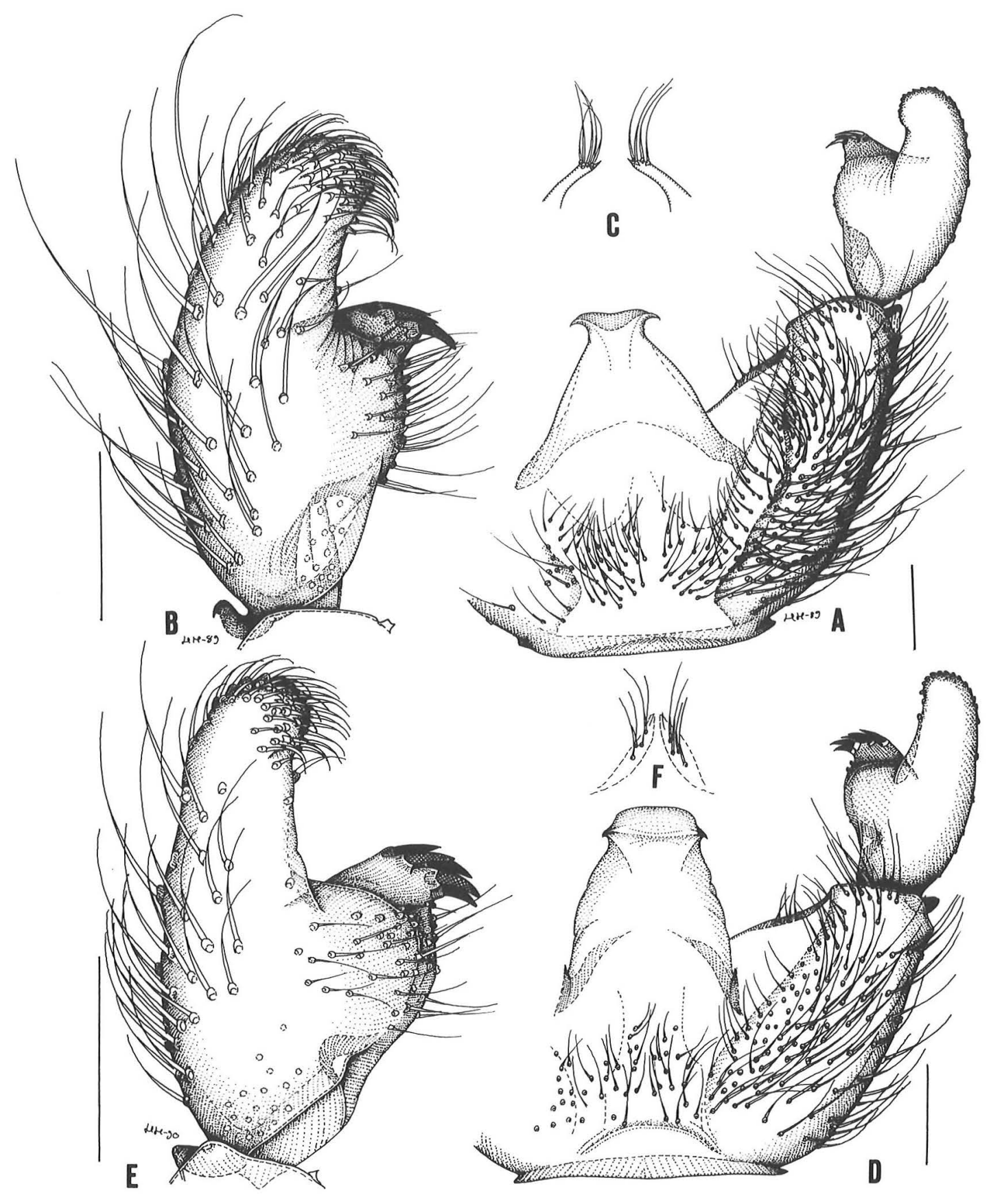

Fig. 14. Part of hypopygium ( $A$ and $D)$, gonostylus ( $B$ and $E)$ and apical part of sternite $10(C$ and $F)$, ventral view. - A, B and C: Prosciara porrecta (Lengersdorf) (Finland). — D, E and F: P. gibbosa sp. n. (holotype). Scale 0.10 $\mathrm{mm}$. 
In addition to the type locality and Tuomikoski's (1960) record from Finland $P$. porrecta has been mentioned from Bayern, Germany (Lengersdorf 1929), Latvia (Lackschewitz 1934) and northern Russia (Gerbachevskaja-Pavluchenko 1986). Frey's (1942) record (female) from Alandia, Finland, according to Tuomikoski (1960), is a misidentification. We have not found this specimen.

$P$. porrecta is similar to $P$. gibbosa. Both species differ from other Prosciara e.g. in the basoventrally inflattened dorsal lobe of the gonostylus, in having a subapical lateral tooth on the tegmen, in having a wide membraneous setose area ventrally between the bases of gonocoxites. $P$. porrecta differs from $P$. gibbosa e.g.: tegmen is strongly tapering towards apex and it is strongly curved dorsad (not well seen in Fig. 14), only slightly tapering and nearly straight in $P$. gibbosa, the dorsal lobe of the gonostylus has four megasetae instead of five and the distal part of the gonostylus is relatively shorter.

\section{Prosciara gibbosa sp. n.}

Material studied: Holotype male: Burma, Kambaiti, 7000 ft, 28.5.1934, R. Malaise (in Stockholm). Paratype o': Burma, Kambaiti, 7000 ft, 12.-17.6.1934, R. Malaise (in Helsinki).

\section{Description}

Head: Eye bridge with 3 rows of facets. Anterior vertex bare. Prefrons with 32-39 setae. Clypeus with 2 setae. Palpal segment 1 with 2 setae. Length/width of flagellar segment 4 of antenna 1.65. - Thorax: Original colour not visible in the specimens studied. Episternum 1 in poor condition in the specimens studied, setae not countable. - Wing: Wing length $3.2 \mathrm{~mm}$. Width/length of wing 0.40 . Tip of wings partially broken in the specimens studied, c/w not measurable. R1/R 0.75-0.95. r-m with 4-10 setae, stM bare, M1 and M2 bare, Cu1 bare and Cu2 bare. - Legs: Femur 1/metatarsus 10.95. Tibia 1 with a comb of 10 setae. Length of spur/ width of tibia 11.55 . Tibia 1 with 0 dorsal, 3 ventral, 0 prolateral and 1 retrolateral spinose setae. Tibia 2 without dorsal spinose setae. Abdomen: Sternite 8 in poor condition in the specimens studied, setae not countable. -
Hypopygium: Fig. 14. Sternite 10 with 3-4 setae on each half.

\section{Discussion}

$P$. gibbosa is similar to $P$. porrecta. For discussion, see under the latter.

\section{Prosciara pectinifera sp. n.}

Material studied: Holotype male: Japan, Mt. Sanageyama, 18.-24.7.1989 (malaise trap), A. Takano (in Ottawa).

\section{Description}

Head: Eye bridge with 3-4 rows of facets. Anterior vertex bare. Prefrons with 22 setae. Clypeus with 4 setae. Palpal segment 1 with 9 setae. Length/width of flagellar segment 4 of antenna 1.60. - Thorax: Dark with paler pleura. Episternum 1 with 8 setae. - Wing: Wing length $2.8 \mathrm{~mm}$. Width/length of wing 0.45 . c/w 0.65 . R1/R 0.90. r-m bare, stM bare, M1 and M2 bare, $\mathrm{Cu} 1$ bare and $\mathrm{Cu} 2$ bare. - Legs: Femur 1/metatarsus 1 1.20. Apex of tibia 1 with a comb of 10 setae. Length of spur/width of tibia 11.10 . Tibia 1 with 0 dorsal, 1 ventral, 0 prolateral and 0 retrolateral spinose setae. Tibia 2 without dorsal spinose setae. - Abdomen: Sternite 8 in poor condition in the specimen studied, setae not visible. - Hypopygium: Fig. 15. Sternite 10 with 1-2 setae on each half.

\section{Discussion}

$P$. pectinifera is an easily recognized species which does not specially resemble any other Prosciara. The evenly broad, strongly oblique dorsal lobe of the gonostylus with the apical megasetae in a row form a unique character complex.

\section{P. furcifera sp. n.}

Material studied: Holotype male: N.E. Burma, Kambaiti, 2000 m, 4.6.1934, Malaise (in Stockholm). Paratype ơ: Burma, Kambaiti, 7000 ft, 1.6.1934, R. Malaise (in Helsinki).

\section{Description}

Head: Eye bridge with 3-4 rows of facets. Anterior vertex with 4 setae. Prefrons with $17-$ 


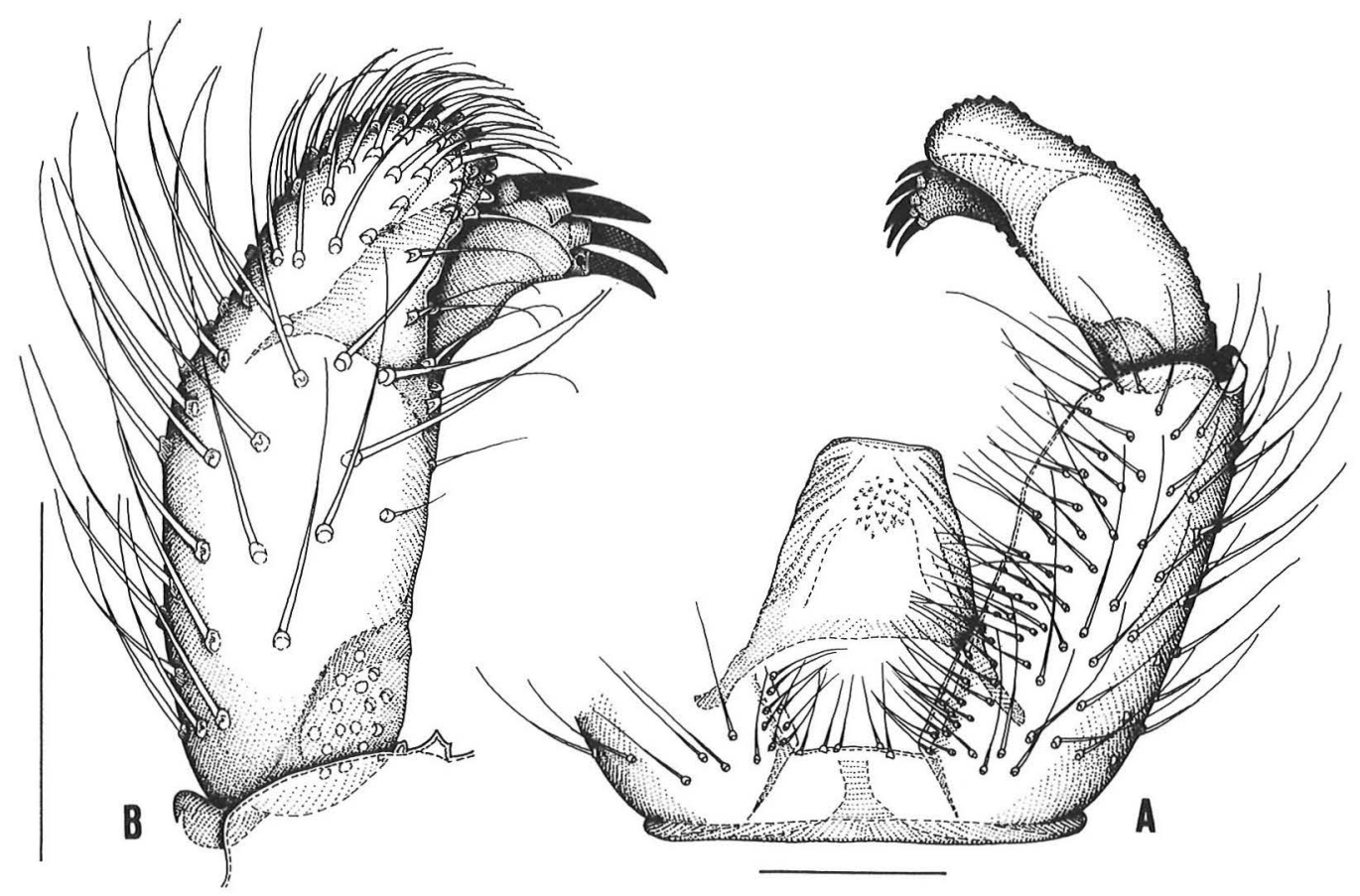

Fig. 15. Prosciara pectinifera sp. n. (holotype): part of hypopygium (A) and gonostylus (B), ventral view. Scale $0.10 \mathrm{~mm}$.

27 setae. Clypeus with 1 seta. Palpal segment 1 with 2 setae. Length/width of flagellar segment 4 of antenna not measured in the specimens studied. - Thorax: Dark with paler pleura. Episternum 1 with 8 setae. - Wing: Wing length 2.6-2.7 mm. Width/length of wing 0.40 . c/w 0.65-0.70. R1/R 0.80-0.85. r-m with 2-3 setae, stM bare, M1 and M2 bare, $\mathrm{Cu} 1$ bare and $\mathrm{Cu} 2$ bare. - Legs: Fig. 18. Femur 1/metatarsus 1 0.95. Apex of tibia 1, Fig. 18. Length of spur/ width of tibia $11.75-1.85$. Tibia 1 with $2-4$ dorsal, 2 ventral, 0 prolateral and 1-2 retrolateral spinose setae. Tibia 2 with 2 dorsal spinose setae. - Abdomen: Sternite 8 with 15 setae. Hypopygium: Fig. 16. Sternite 10 with 1 seta.

\section{Discussion}

$P$. furcifera is very similar to $P$. processifera and $P$. latifurca. The distinguishing characters are discussed under $P$. latifurca.

\section{Prosciara processifera $\mathbf{s p .} \mathbf{n}$.}

Material studied: Holotype male: Burma, Kambaiti, 6800 ft, 5.4.1934, R. Malaise (in Stockholm). Paratypes: Burma, Kambaiti, 7000 ft, 28.5.1934, R. Malaise, $10^{7}$ (in Stockholm); Burma, Kambaiti, 7000 ft, 1.6.1934, R. Malaise, 10 (in Stockholm); Burma, Kambaiti, 7000 ft, 12.17.6.1934, R. Malaise, $20^{\top} \sigma^{\top}$ (in Stockholm); N.E. Burma, Kambaiti, 2000 m, 31.3.1934, Malaise, 10 (in Helsinki); N.E. Burma, Kambaiti, 7000 ft, 11.5.1934, Malaise, $20^{7} \sigma^{7}$ (in Helsinki and in London).

\section{Description}

Head: Eye bridge with 3-4 rows of facets. Anterior vertex with 2-5 setae. Prefrons with 14-40 setae. Clypeus with 1 seta. Palpal segment 1 with 2-3 setae. Length/width of flagellar segment 4 of antenna 1.75-1.90. - Thorax: Original colour not visible in the specimens studied. Episternum 1 with 4-8 setae. - Wing: Wing length $2.7-3.0 \mathrm{~mm}$. Width/length of wing 0.40 . 


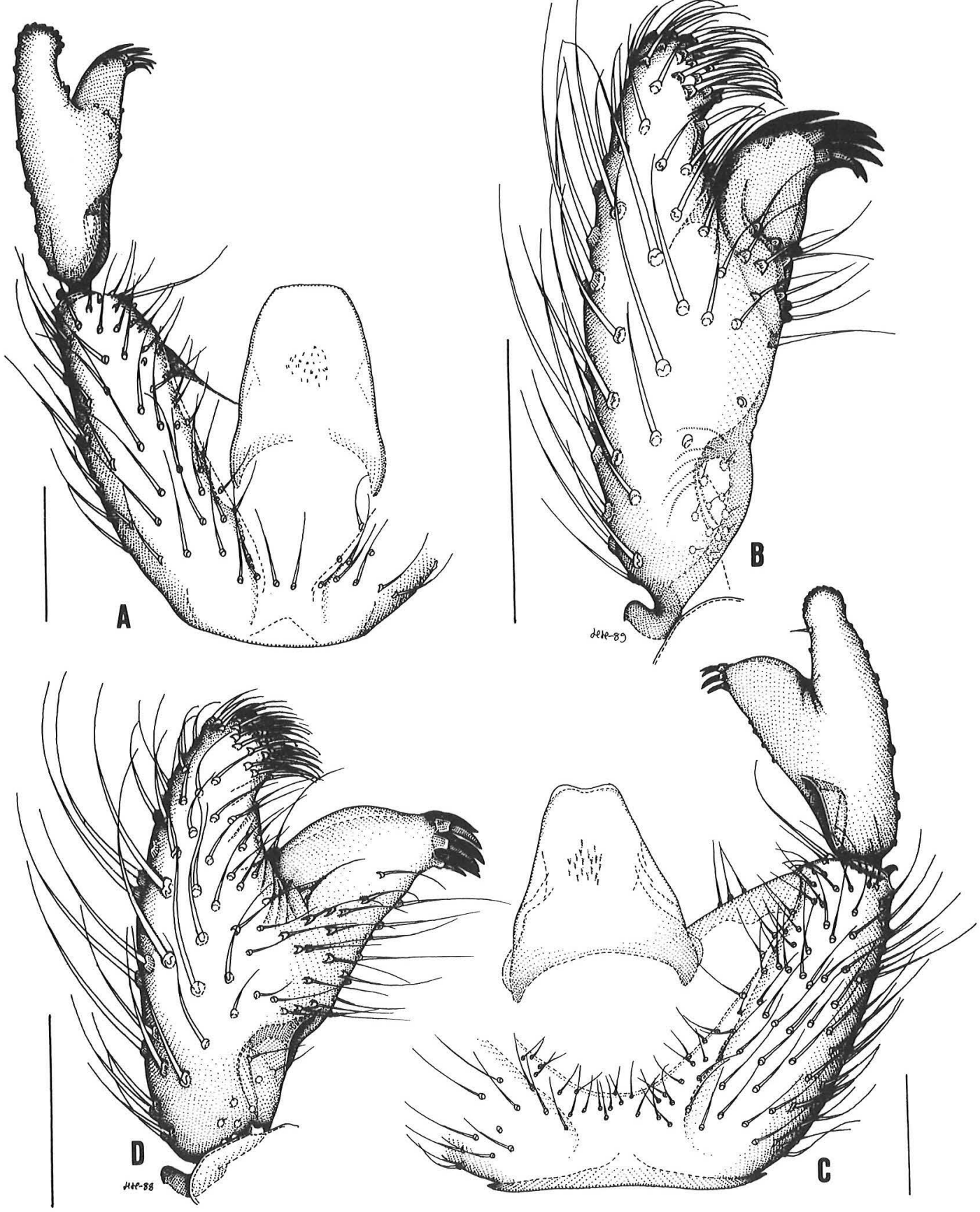

Fig. 16. Part of hypopygium ( $A$ and $C$ ) and gonostylus ( $B$ and $D)$, ventral view. - A and B: Prosciara furcifera sp. n. (holotype). $-C$ and D: P. latifurca sp. n. (holotype). Scale $0.10 \mathrm{~mm}$. 


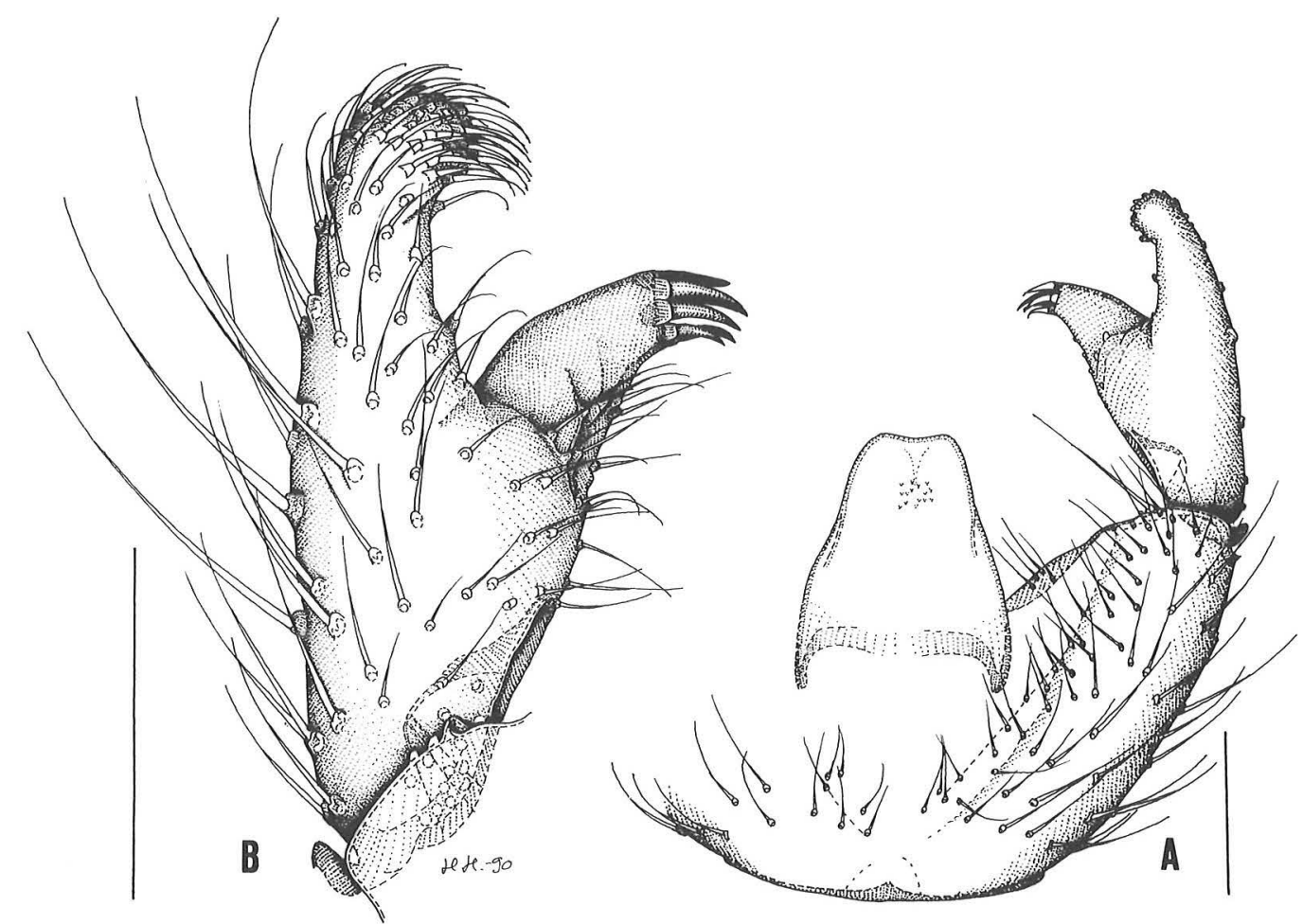

Fig. 17. Prosciara processifera sp. n. (holotype): part of hypopygium (A) and gonostylus (B), ventral view. Scale $0.10 \mathrm{~mm}$.

c/w 0.55-0.70. R1/R 0.75-0.95. r-m with 1-4 setae, stM bare, M1 and M2 bare, $\mathrm{Cu} 1$ bare and $\mathrm{Cu} 2$ bare. - Legs: Femur 1/metatarsus 1 1.001.05. Apex of tibia 1 with a comb of 7-11 setae. Length of spur/width of tibia 1 1.65-1.95. Tibia 1 with 2-3 dorsal, 1-3 ventral, 0 prolateral and 1-3 retrolatral spinose setae. Tibia 2 with $2-3$ dorsal spinose setae. - Abdomen: Sternite 8 in poor condition in the specimens studied, setae not countable. - Hypopygium: Fig. 17. Sternite 10 with $1-2$ setae on each half.

\section{Discussion}

$P$. processifera is very similar to $P$. furcifera and $P$. latifurca. For distinguishing characters, see under $P$. latifurca.

\section{Prosciara latifurca sp. n.}

Material studied: Holotype male: N.E. Burma, Kambaiti, 2000 m, 23.5.1934, Malaise (in Stockholm). Paratypes: N.E. Burma, Kambaiti, 2000 m, 9.6.1934, Ma- laise, $10^{\top}$ (in Stockholm); N.E. Burma, Kambaiti, 2000 m, 11.5.1934, Malaise, 10 (in Stockholm); a specimen with two labels: N.E. Burma, Kambaiti, 2000 m, 11.5.1934, Malaise and N.E. Burma, Kambaiti, 2000 m, 13.5.1934, Malaise, (in Helsinki); Burma, Kambaiti, 6800 ft, 5.4..1934, R. Malaise, $10^{\top}$ (in Helsinki); Burma, Kambaiti, $7000 \mathrm{ft}$, 17.4.1934, R. Malaise, $1 \sigma^{3}$ (in London).

\section{Description}

Head: Eye bridge with 3-4 rows of facets. Anterior vertex with 0-6 setae. Prefrons with 21-31 setae. Clypeus with 1-2 setae. Palpal segment 1 with 2-3 setae. Length/width of flagellar segment 4 of antenna 2.10-2.30. — Thorax: Dark with paler pleura. Episternum 1 with 6-14 setae. - Wing: Wing length 3.2-3.4 mm. Width/length of wing $0.35-0.45$. c/w $0.55-0.60$. R1/R $0.90-$ 1.00. $\mathrm{r}-\mathrm{m}$ with $1-3$ setae, stM bare, M1 and M2 bare, $\mathrm{Cu} 1$ bare and $\mathrm{Cu} 2$ bare. - Legs: Fig. 18. Femur 1/metatarsus 1 0.95-1.00. Apex of tibia 1, Fig. 18. Length of spur/width of tibia 1 1.752.10. Tibia 1 with $3-4$ dorsal, 4-7 ventral, 0 prolateral and 3 retrolateral spinose setae. Tibia 2 with 2-3 dorsal spinose setae. - Abdomen: 


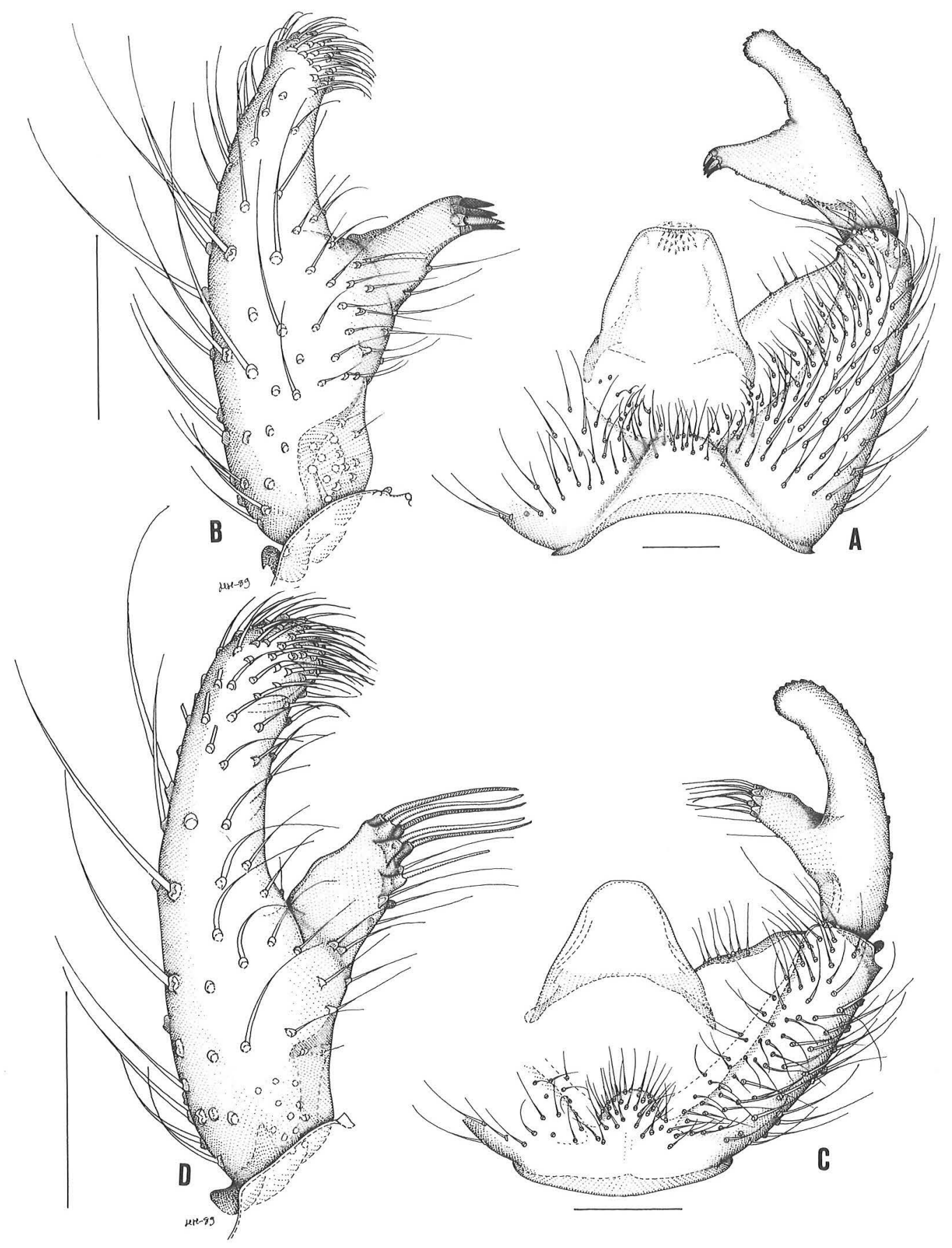

Fig. 19. Part of hypopygium ( $A$ and $C$ ) and gonostylus ( $B$ and $D)$, ventral view. - A and B: Prosciara pollex sp. $n$. (holotype). - C and D: P. dolichochaeta sp. n. (holotype). Scale $0.10 \mathrm{~mm}$. 
Sternite 8 with $8-15$ setae. - Hypopygium: Fig. 16. Sternite 10 with $1-2$ setae on each half.

\section{Discussion}

$P$. latifurca, $P$. processifera and $P$. furcifera are all very similar to each other. $P$. furcifera differs from the two others in having fewer and stronger setae on the gonoscoxites and in having two strong setae in the membrane between the bases of the gonoscoxites instead of several weak ones. $P$. latifurca and $P$. processifera can be distinguished by the dorsal lobe of the gonostylus which in the former is broad and fairly abruptly narrowed near its apex, in the latter the lobe is much narrower and steadily narrows towards apex. Fairly certainly $P$. latifurca can be expected to differ from the two others by its larger size: wing length 3.2-3.4 $\mathrm{mm}$ versus $2.6-2.7 \mathrm{~mm}$ in $P$. furcifera and $2.7-3.0 \mathrm{~mm}$ in $P$. processifera.

\section{Prosciara pollex sp. n.}

Material studied: Holotype male: N.E. Burma, Kambaiti, 2000 m, 17.5.1934, Malaise (in Stockholm). Paratypes: Burma, Kambaiti, 7000 ft, 25.5.1934, R. Malaise, $40^{\top} 0^{7}$, (in Stockholm, in Helsinki and in London).

\section{Description}

Head: Eye bridge with 3-4 rows of facets. Anterior vertex with 3-5 setae. Prefrons with 23-34 setae. Clypeus with 1-2 setae. Palpal segment 1 with 2 setae. Antennae missing in the specimens studied. - Thorax: Dark with paler pleura. Episternum 1 with 7-11 setae. - Wing: Wing length $3.4-3.6 \mathrm{~mm}$. Width/length of wing 0.40. c/w 0.50-0.60. R1/R 0.90-1.10. r-m with 9-14 setae, stM with a few setae, M1 and M2 with numerous setae, $\mathrm{Cu} 1$ with numerous setae and $\mathrm{Cu} 2$ bare. - Legs: Fig. 18. Femur 1/metatarsus 10.95 . Apex of tibia 1 with a comb of $8-$ 11 setae, Fig. 18. Length of spur/width of tibia 1 2.20-2.30. Tibia 1 with 7 dorsal, 10 ventral, 7 prolateral and 5 retrolateral spinose setae (only holotype measured). Tibia 2 with 5 dorsal spinose setae. - Abdomen: Sternite 8 with 15-17 setae. - Hypopygium: Fig. 19. Sternite 10 with 1-3 setae on each half.

\section{Discussion}

The hypopygium of $P$. pollex recalls $P$. latifurca, $P$. processifera and $P$. furcifera on the one hand and $P$. angustiloba and $P$. megachaeta on the other. From the former two the hypopygium differs e. $g$. in the presence of an intercoxal lobe and from the two latter in this lobe being short, and in tegmen narrowing towards apex. From all these species $P$. pollex is distinguished in having the membrane adjacent to the ventral mesial margin of the gonocoxites richly setose.

\section{Prosciara dolichochaeta sp. n.}

Material studied: Holotype male: N.E. Burma, Kambaiti, 2000 m, 4.6.1934, Malaise (in Stockholm) Paratypes: Burma, Kambaiti, 6800 ft, 7.4.1934, R. Malaise, $10^{\top}$ (in Stockholm); Burma, Kambaiti, $7000 \mathrm{ft}$, 17.4.1934, $10^{\text {' }}$ (in Helsinki); Burma, Kambaiti, $7000 \mathrm{ft}$, 25.5.1934, R. Malaise, $10^{7}$ (in London).

\section{Description}

Head: Eye bridge with 3-4 rows of facets. Anterior vertex with 0-6 setae. Prefrons with 15-25 setae. Clypeus with 1-2 setae. Palpal segment 1 with 5 setae. Length/width of flagellar segment 4 of antenna 2.30. - Thorax: Dark with paler pleura. Episternum 1 with 7-12 setae. Wing: Wing length $3.1-3.3 \mathrm{~mm}$. Width/length of wing 0.45 . c/w 0.60. R1/R 1.00. r-m with $0-1$ seta, stM bare, M1 and M2 bare, $\mathrm{Cu} 1$ bare and $\mathrm{Cu} 2$ bare. — Legs: Femur 1/metatarsus 1 0.90. Tibia 1 with a comb of 9-11 setae. Length of spur/width of tibia 1 2.15. Tibia 1 with 4 dorsal, 2 ventral, 0 prolateral and ?1 retrolateral spinose setae. Tibia 2 with 4 dorsal spinose setae. - Abdomen: Sternite 8 with 15-16 setae. - Hypopygium: Fig. 19. Sternite 10 with 1-2 setae on each half.

\section{Discussion}

$P$. dolichochaeta, $P$. filichaeta and $P$. decamera resemble each other and differ from other known Prosciara in having the megasetae on the dorsal lobe of the gonostylus unusually slender and the lobe itself very basal in position. $P$. dolichochaeta differs from the two others e. $g$. in the relatively much longer megasetae and narrow apical part of the gonostylus in ventral view. $P$. filichaeta differs from the others e.g. in lacking the intercoxal lobe of hypopygium and in having setose $\mathrm{M}, \mathrm{Cu} 1$ and $\mathrm{Cu} 2$. P. decamera differs from the others in having more than 10 , usually 12 , megasetae on the dorsal lobe of the gonostylus instead of five or six. 


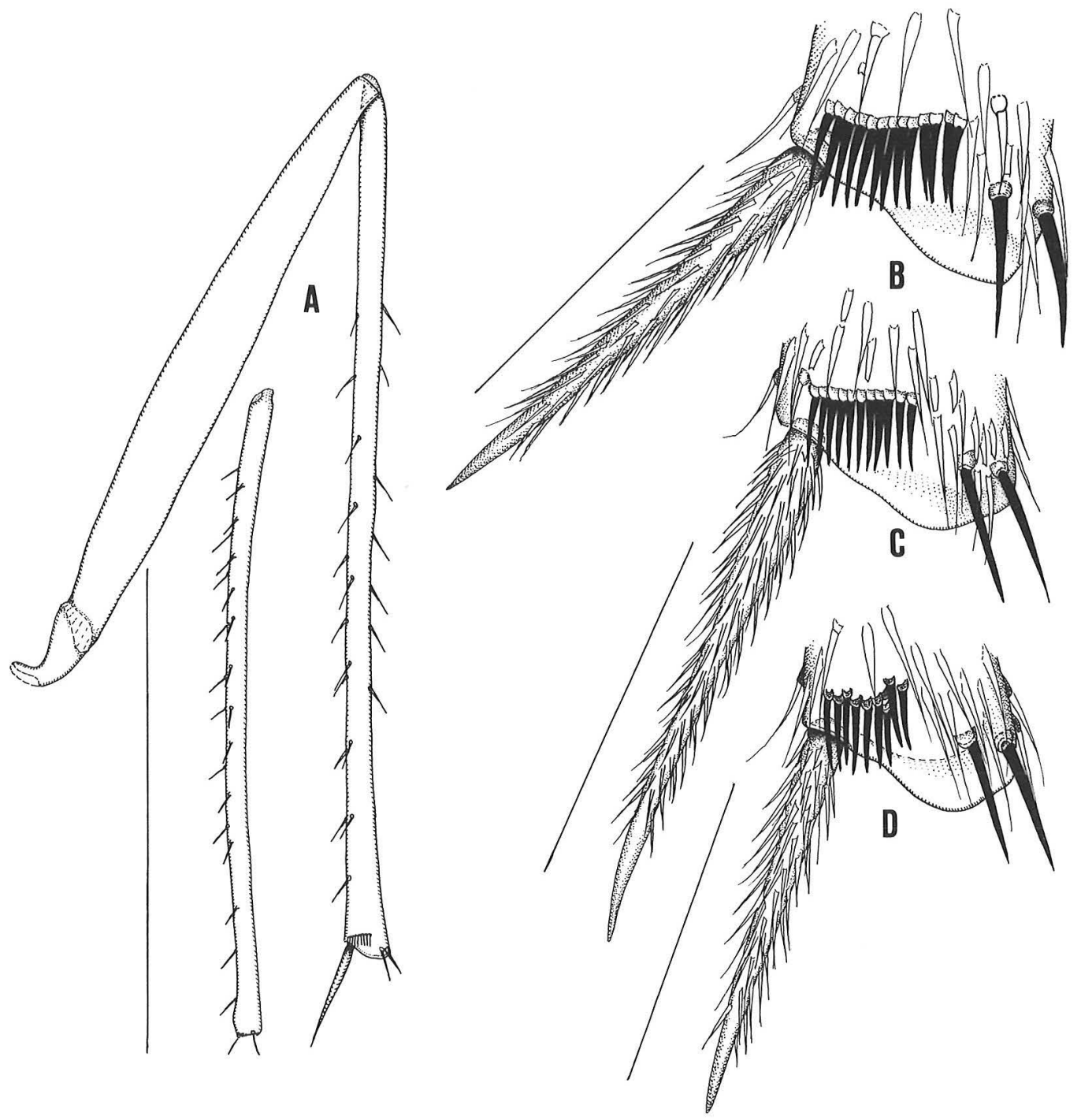

Fig. 18. Front trochanter, femur, tibia and detached metatarsus (A) and apex of front tibia (B-D), prolateral view. A and C: Prosciara pollex sp. n. (holotype). - B: P. latifurca sp. n. (paratype). - D: P. furcifera sp. n. (holotype). Scale for A $0.50 \mathrm{~mm}$, for B-D $0.10 \mathrm{~mm}$.

\section{Prosciara filichaeta sp. n.}

Material studied: Holotype male: Burma, Kambaiti, $7000 \mathrm{ft}, 1.6 .1934$, R. Malaise (in Stockholm). Paratypes: same data as in the holotype, $30^{\circ} 0^{7}$ (in Stockholm and in London); Burma, Kambaiti, 7000 ft, 12.-17.6.1934, R. Malaise, $1 \sigma^{\text {T }}$ (in Helsinki); Nepal, Pheol Chuki, $8000 \mathrm{ft}$, 17.8.1967, Canad. Nepal Exp., $10^{7}$ (in Ottawa).

\section{Description}

Head: Eye bridge with 3 rows of facets. Anterior vertex bare. Prefrons with 20-36 setae. Clypeus with 0-2 setae. Palpal segment 1 with 2-3 setae. Length/width of flagellar segment 4 of antenna 2.50-2.80. - Thorax: Original colour not visible in the specimens studied. Episternum 
1 with 3-10 setae. - Wing: Wing length $3.5 \mathrm{~mm}$. Width/length of wing 0.40 . c/w $0.55-0.60$. R1/R 0.80-1.00. $\mathrm{r}-\mathrm{m}$ with 0-1 seta, stM with a few setae, M1 and M2 with numerous setae, Cu1 with numerous setae and $\mathrm{Cu} 2$ with numerous setae. Legs: Femur 1/metatarsus 1 0.95. Apex of tibia with a comb of $8-13$ setae. Length of spur/width of tibia 1 1.80-2.10. Tibia 1 with 3 dorsal, 3-6 ventral, 0 prolateral and 1-3 retrolateral spinose setae. Tibia 2 with 2 dorsal spinose setae. - Abdomen: Sternite 8 with 15 setae. - Hypopygium: Fig. 20. Sternite 10 with $1-3$ setae on each half.

Discussion

$P$. filichaeta resembles $P$. dolichochaeta and $P$. decamera. For distinguishing characters, see under $P$. dolichochaeta. $P$. filichaeta differs from all other Prosciara except $P$. producta in having a setose $\mathrm{Cu} 2$. Respecting the characters of the gonostylus these two species belong to quite different structural types.

\section{Prosciara decamera sp. n.}

Material studied: Holotype male: Burma, Kambaiti, 7000 ft, 1.6.1934, R. Malaise (in Stockholm). Paratypes: same data as in the holotype, $10^{7}$ (in Stockholm); Burma, Kambaiti, 7000 ft, 25.5.1934, R. Malaise, $10^{7}$ (in Stockholm); Burma, Kambaiti, 6800 ft, 7.4.1934, R. Malaise, $10^{7}$ (in Helsinki); Burma, Kambaiti, 7000 ft, 12.-17.6.1934, R. Malaise, $10^{\prime}$ (in Helsinki).

\section{Description}

Head: Eye bridge with 4-5 rows of facets. Anterior vertex with 0-4 setae. Prefrons with 17-26 setae. Clypeus with 0-2 setae. Palpal segment 1 with 2 setae. Length/width of flagellar segment 4 of antenna not measured. - Thorax: Original colour not visible in the specimens studied. Episternum 1 with 4-8 setae. - Wing: Wing length $2.7-3.2 \mathrm{~mm}$. Width/length of wing 0.40 . c/w $0.55-0.65$. R1/R 0.75-0.90. r-m 0-1 seta, stM bare, M1 and M2 bare, $\mathrm{Cu} 1$ bare and $\mathrm{Cu} 2$ bare. - Legs: Femur 1/ metatarsus 10.85 . Apex of tibia with a comb of 8 10 setae. Length of spur/width of tibia 12.00 . Tibia 1 with 4-6 dorsal, 2-5 ventral, 0-1 prolateral and 1 retrolateral spinose setae. Tibia 2 with $2-3$ dorsal spinose setae. - Abdomen: Sternite 8 with 10-19 setae. - Hypopygium: Fig. 21. Sternite 10 with $1-$ 2 setae on each half.

\section{Discussion}

$P$. decamera resembles $P$. dolichochaeta and $P$. filichaeta in the general structure of the gonostylus, including the slender megasetae of the dorsal lobe. The high number of megasetae, about 12 , distinguishes $P$. decamera from all other known Prosciara. See also under P. dolichochaeta.

\section{Prosciara megacera sp. n.}

Material studied: Holotype male: Burma, Kambaiti, 7000 ft, 17.4.1934, R. Malaise (in Stockholm).

\section{Description}

Head: Eye bridge with 3 rows of facets. Anterior vertex with 7 setae. Prefrons with 18 setae. Clypeus with 2 setae. Palpal segment 1 with 2 setae. Length/width of flagellar segment 4 of antenna not measured in the specimen studied. - Thorax: Original colour not visible in the specimen studied. Episternum 1 with 8 setae. Wing: Wing length $3.0 \mathrm{~mm}$. Width/length of wing 0.40 . c/w 0.65. R1/R 1.00. r-m bare, stM bare, $\mathrm{M} 1$ and $\mathrm{M} 2$ bare, $\mathrm{Cu} 1$ bare and $\mathrm{Cu} 2$ bare. - Legs: Femur 1/metatarsus 1 1.05. Apex of tibia with a comb of 10 setae. Length of spur/ width of tibia 1 not measurable in the specimen studied. Tibia 1 with 4 dorsal, 7 ventral, 0 prolateral and 2 retrolateral spinose setae. Tibia 2 with 5 dorsal spinose setae. - Abdomen: Sternite 8 in poor condition in the specimen studied, setae not countable. - Hypopygium: Fig. 22. Sternite 10 with 1-2 setae on each half.

\section{Discussion}

$P$. megacera is not very similar to any other known species of Prosciara. From any reminiscent species it is distinguished in having only one apical megaseta on the gonostylus and in the very large dorsal lobe of the gonostylus, with one of the megasetae more basal in position than the others.

\section{Prosciara tetrix sp. n.}

Material studied: Holotype male: Burma, Kambaiti, 7000 ft, 1.6.1934, R. Malaise (in Stockholm). Paratypes: same data as in the holotype, $10^{7}$ (in Stockholm); Burma, Kambaiti, $7000 \mathrm{ft}, 12 .-17.6 .1934$, R. Malaise, $20^{7} \mathrm{o}^{7}$ (in Helsinki). 




Fig. 20. Prosciara filichaeta sp. n. (D and C holotype, A, B and E paratype): part of hypopygium (A and C), gonostylus $(B$ and $D)$ and the apex of the dorsal lobe of gonostylus $(E)$, ventral view. Scale $0.10 \mathrm{~mm}$. 


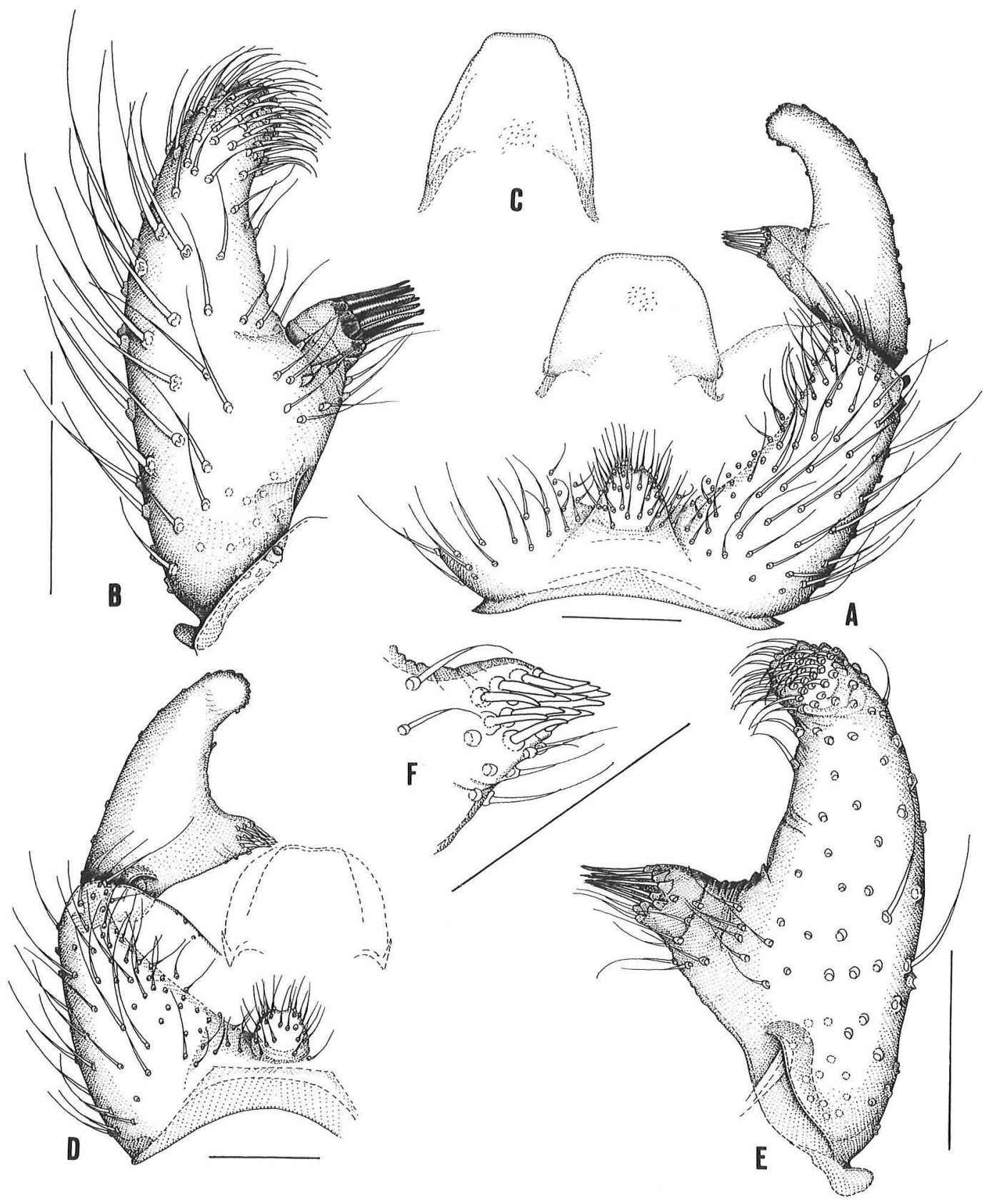

Fig. 21. Prosciara decamera sp. n. (A and B holotype, C paratype, D, E and F another paratype): part of hypopygium ( $A$ and $D$ ), gonostylus ( $B$ and $E$ ), tegmen $(C)$, and the dorsal lobe of gonostylus of $D$ more enlarged $(\mathrm{F})$, all ventral view. Scale $0.10 \mathrm{~mm}$. 


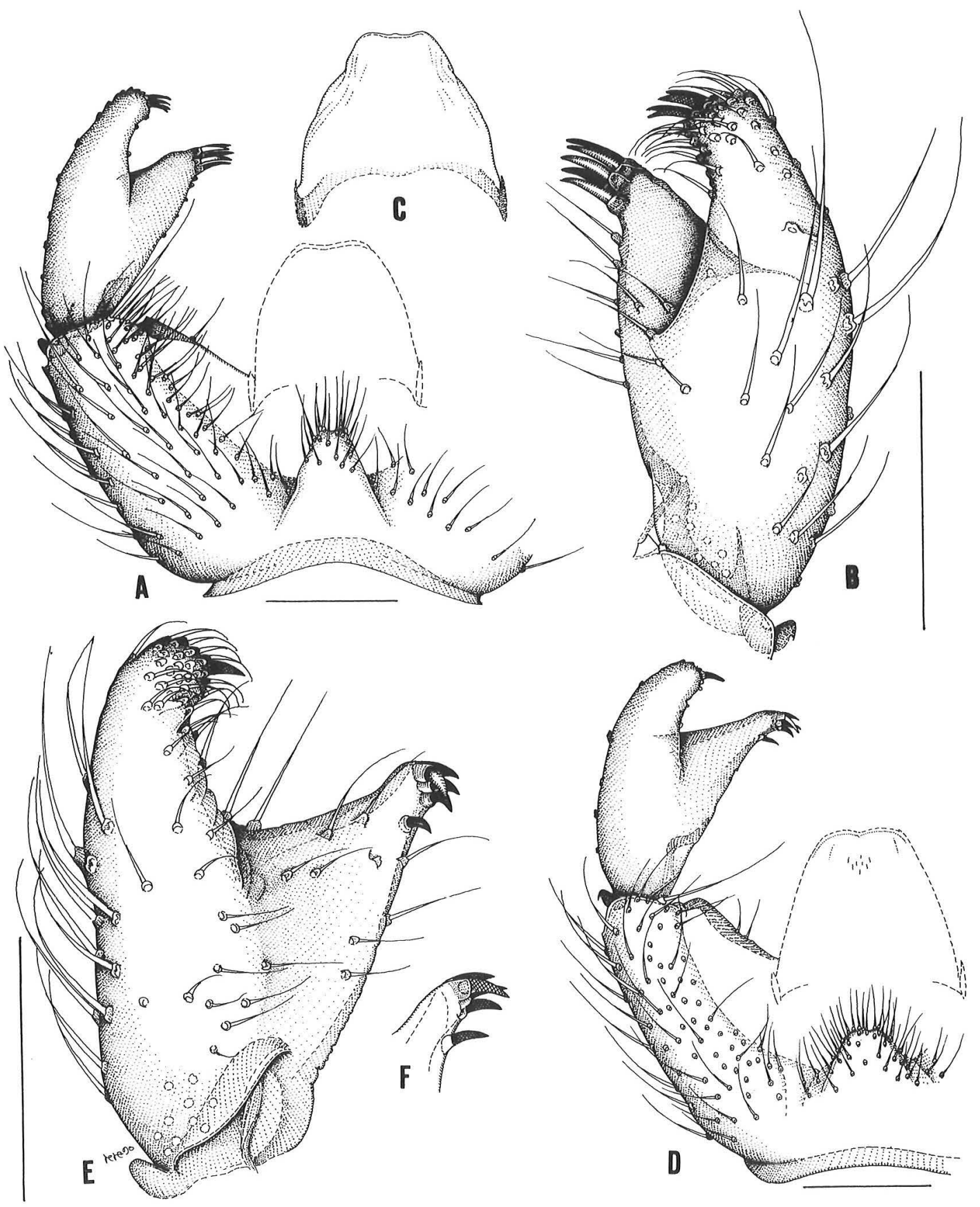

Fig. 22. Part of hypopygium ( $A$ and $D$ ), gonostylus ( $B$ and $E$ ), tegmen $(C)$ and the apex of the dorsal lobe of gonostylus (F), ventral view. - A, B and C: Prosciara tetrix sp. n. (A and B holotype, C paratype). - D, E and F: P. megacera sp. n. (holotype). Scale $0.10 \mathrm{~mm}$. 


\section{Description}

Head: Eye bridge with 3-4 rows of facets. Anterior vertex with 3-9 setae. Prefrons with 19-29 setae. Clypeus with 2 setae. Palpal segment 1 with 2-4 setae. Length/width of flagellar segment 4 of antenna 2.80. - Thorax: Original colour not visible in the specimens studied. Episternum 1 with 8 setae. - Wing: Wing length $2.8-3.2 \mathrm{~mm}$. Width/length of wing $0.40-0.45$. c/ w 0.60-0.65. R1/R 0.85. r-m bare, stM bare, M1 and $\mathrm{M} 2$ bare, $\mathrm{Cu} 1$ bare and $\mathrm{Cu} 2$ bare. Legs: Femur $1 /$ metatarsus 1 not measurable in the specimens studied (legs in poor condition). Apex of tibia 1 with a comb of $8-11$ setae. Length of spur/width of tibia $11.95-2.00$. Tibia 1 with 3-4 dorsal, 3 ventral, 0 prolateral and 2-4 retrolateral spinose setae. Tibia 2 with 3-7 dorsal spinose setae. - Abdomen: Sternite 8 with 11-12 setae. - Hypopygium: Fig. 22. Sternite 10 with 1 seta on each half.

\section{Discussion}

$P$. tetrix is similar to $P$. duplex, $P$. biloba and $P$. biceps in having several strong megasetae at the apex of the gonostylus. It differs from all of these in much stronger intercoxal lobe of the hypopygium, from $P$. duplex by oblique dorsal lobe of the gonostylus, from $P$. biloba and $P$. biceps by broad apical part of the gonostylus and from $P$. duplex and $P$. biloba by long megasetae on the dorsal lobe of the gonostylus.

\section{Prosciara duplex sp. n.}

Material studied: Holotype male: Specimen with two labels: N.E. Burma, Kambaiti, 2000 m, 4.6.1934, Malaise; the other label with the same data but 7.6.1934 (in Stockholm). Paratypes: N.E. Burma, Kambaiti, 2000 m, 11.5.1934, Malaise, $10^{7}$ (in Stockholm) and N.E. Burma, Kambaiti, 2000 m, 4.6.1934, Malaise, $20^{\top} 0^{7}$ (in Helsinki); Burma, Kambaiti, 7000 ft, 17.4.1934, R. Malaise, $10^{7}$ (in Stockholm); Burma, Kambaiti, 7000 ft, 1.6.1934, R. Malaise, $40^{\top} \mathrm{O}^{\top}$ (in Stockholm, in Helsinki and in London).

\section{Description}

Head: Eye bridge with 4-5 rows of facets. Anterior vertex with $2-10$ setae. Prefrons with 14-26 setae. Clypeus with 0-1 seta. Palpal segment 1 with 2-3 setae. Length/width of flagellar segment 4 of antenna 2.50. - Thorax: Dark with paler pleura. Episternum 1 with 5-10 setae.
— Wing: Fig. 12. Wing length 2.9-3.2 mm. Width/ length of wing 0.40 . c/w 0.60-0.70. R1/R 0.95. r-m bare, stM bare, $\mathrm{M} 1$ and $\mathrm{M} 2$ bare, $\mathrm{Cu} 1$ bare and $\mathrm{Cu} 2$ bare. - Legs: Femur 1/metatarsus 1 0.90. Apex of tibia 1 with a comb of 9-10 setae. Length of spur/ width of tibia 1 1.90-2.10. Tibia 1 with 3-5 dorsal, 4-5 ventral, 0 prolateral and 2-3 retrolateral spinose setae. Tibia 2 with 6-7 dorsal spinose setae. Abdomen: Sternite 8 with 14-20 setae. Hypopygium : Figs. 23 and 24. Sternite 10 with 1 seta on each half.

\section{Discussion}

$P$. duplex is similar to $P$. tetrix, $P$. biloba and $P$. biceps, all of which have several apical megasetae on the gonostylus. It differs from all of these in having the dorsal lobe of the gonostylus transversal, not oblique, more basal in position and also relatively longer. Further, it differs from $P$. tetrix in weaker intercoxal lobe of hypopygium, from $P$. biloba and $P$. biceps in broad apical part of the gonostylus and from $P$. tetrix and $P$. biceps in relatively short megasetae on the dorsal lobe of the gonostylus.

\section{Prosciara biloba sp. $\mathrm{n}$.}

Material studied: Holotype male: N.E. Burma, Kambaiti, 2000 m, 4.6.1934, Malaise (in Stockholm). Paratypes: N.E. Burma, Kambaiti, 7000 ft, Malaise, $10^{7}$ (in Stockholm) and N.E. Burma, $2000 \mathrm{~m}, 4$ 4.6.1934, Malaise, $1 \sigma^{7}$ (in Helsinki); Burma, Kambaiti, $7000 \mathrm{ft}, 1.6 .1934, \mathrm{R}$. Malaise, $1 \sigma^{7}$ (in Stockholm).

\section{Description}

Head: Eye bridge with 3-4 rows of facets. Anterior vertex with 2 setae. Prefrons with $21-$ 24 setae. Clypeus with 0-3 setae. Palp, Fig. 23, palpal segment 1 with 2 setae. Antennae missing or in poor condition in the specimens studied. Thorax: Dark with paler pleura. Episternum 1 with 6-8 setae. - Wing: Wing length $2.7-2.8$ $\mathrm{mm}$. Width/length of wing 0.40 . c/w 0.60 . R1/R 0.75. r-m bare, stM bare, M1 and M2 bare, $\mathrm{Cu} 1$ bare and $\mathrm{Cu} 2$ bare. - Legs: Femur 1/metatarsus 1 0.95. Apex of tibia 1, Fig. 23. Length of spur/ width of tibia 1 1.85-1.90. Tibia 1 with 3 dorsal, 2 ventral, 0 prolateral and 3 retrolateral spinose setae. Tibia 2 with 4 dorsal spinose setae. - Abdomen: Sternite 8 with 12 setae. - Hypopygium: Fig. 23. Sternite 10 with 2 setae on each half. 


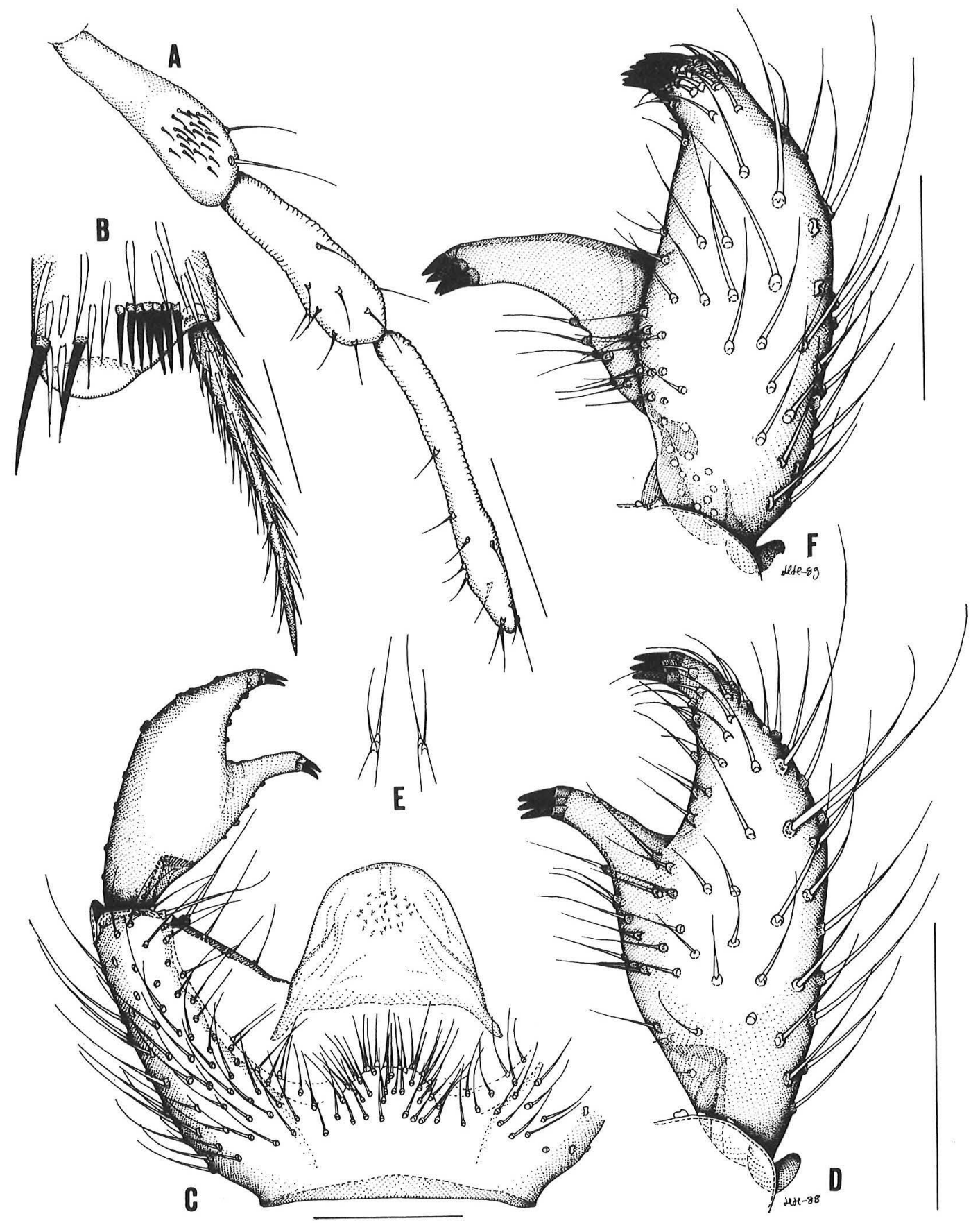

Fig. 23. Maxillary palp (A), dorsal view, apex of front tibia (B), prolateral view, part of hypopygium (C), gonostylus (D and F) and apical part of sternite $10(\mathrm{E})$, ventral view. - A-E: Prosciara biloba sp. n. (A and B paratypes, CE holotype). - F: P. duplex sp. n. (paratype). Scale $0.10 \mathrm{~mm}$. 


\section{Discussion}

P. biloba is very similar to $P$. biceps. It is distinguished from $P$. biceps by narrower dorsal lobe of the gonostylus and much shorter megasetae both on apex and on the dorsal lobe of the gonostylus. $P$. biloba and $P$. biceps are similar to $P$. tetrix and $P$. duplex. For discussion, see under the latter two.

\section{Prosciara biceps sp. $\mathbf{n}$.}

Material studied: Holotype male: Burma, Kambaiti, 7000 ft, 25.5.1934, R. Malaise (in Stockholm). Paratype o': Burma, Kambaiti, 7000 ft, 12.-17.6.1934, R. Malaise (in Helsinki).

\section{Description}

Head: Eye bridge with 3 rows of facets. Anterior vertex with 2-3 setae. Prefrons with 16-25 setae. Clypeus with 1 seta. Palpal segment 1 with 3 setae. Length/width of flagellar segment 4 of antenna 2.70. — Thorax: Original colour not visible in the specimens studied. Episternum 1 in poor condition in the specimens studied, setae not countable. - Wing: Wing length $2.6 \mathrm{~mm}$. Width/length of wing 0.40 . c/w 0.55 . R1/R 0.60 0.70. r-m bare, stM bare, M1 and M2 bare, $\mathrm{Cu} 1$ bare and $\mathrm{Cu} 2$ bare. - Legs: Femur 1/metatarsus 1 not measured (legs in poor condition in the specimens studied). Tibia 1 with a comb of 8 setae. Length of spur/width of tibia 1 not measured in the specimens studied. Tibia 1 with 3 dorsal, 4 ventral, 0 prolateral and 2 retrolateral spinose setae. Tibiae 2 in poor condition in the specimens studied, spinose setae not countable. - Abdomen: Sternite 8 in poor condition in the specimens studied, setae not countable. - Hypopygium: Fig. 24. Sternite 10 with 1 seta on each half.

\section{Discussion}

$P$. biceps is similar to $P$. biloba. For discussion, see under the latter.

\section{Prosciara gemellata sp. n.}

Material studied: Holotype male: Burma, Kambaiti, 7000 ft, 1.6.1934, R. Malaise (in Stockholm). Paratypes: Burma, Kambaiti, 7000 ft, 28.5.1934, R. Malaise, $20^{7} \mathrm{O}^{7}$ (in Stockholm); Burma, Kambaiti, 7000 ft, 12.-17.6.1934, R. Malaise, $1 \sigma^{7}$ (in Helsinki).

\section{Description}

Head: Eye bridge with 3-4 rows of facets. Anterior vertex with 6-8 setae. Prefrons with 12-30 setae. Clypeus with 1-2 setae. Palpal segment 1 with $2-3$ setae. Length/width of flagellar segment 4 of antenna 2.50. - Thorax: Original colour not visible in the specimens studied. Episternum 1 with 5-7 setae. - Wing: Wing length 3.1-3.4 mm. Width/length of wing 0.350.40 . c/w 0.55-0.60. R1/R 0.80-0.90. r-m with 0-2 setae, stM bare, M1 and M2 bare, Cu1 bare and $\mathrm{Cu} 2$ bare. - Legs: Femur 1/metatarsus 1 not measured in the specimens studied (legs in poor condition in the specimens studied). Apex of tibia 1 with a comb of 7-12 setae. Length of spur/width of tibia 11.95 . Tibia 1 with $3-5$ dorsal, 4-6 ventral, 0 prolateral and 2-4 retrolateral spinose setae. Tibia 2 with 3-7 dorsal spinose setae. - Abdomen: Sternite 8 with 11 setae. Hypopygium: Fig. 25. Sternite 10 with $1-2$ setae on each half.

\section{Discussion}

$P$. gemellata is similar to $P$. triloba. Both species differ from other known Prosciara in having two separate dorsal lobes on the gonostylus. In $P$. gemellata the lobes are situated close to one another, in ventral aspect usually partially overlapping, in $P$. triloba they are separated by a gap at least as broad as the width of the lobes.

\section{Prosciara triloba sp. n.}

Material studied: Holotype male: N.E. Burma, Kambaiti, 2000 m, 7.6.1934, Malaise (in Stockholm). Paratypes: Burma, Kambaiti, 7000 ft, 13.4.1934, R. Malaise, $10^{7}$ (in Stockholm); Burma, Kambaiti, 7000 ft, 28.5.1934, R. Malaise, $10^{7}$ (in Stockholm); Burma, Kambaiti, 7000 ft, 12.-17.6.1934, R. Malaise, $10^{7}$ (in Helsinki).

\section{Description}

Head: Eye bridge with 3-4 rows of facets. Anterior vertex with 5-8 setae. Prefrons with 22-24 setae. Clypeus with 0-1 seta. Palpal segment 1 with 2 setae. Length/width of flagellar segment 4 of antenna 2.70. - Thorax: Dark with paler pleura. Episternum 1 with 7-8 setae. Wing: Wing length $2.8-3.5 \mathrm{~mm}$. Width/length of wing 0.40 . $\mathrm{c} / \mathrm{w} 0.60-0.70$. R1/R 0.65-1.00. r-m bare, stM bare, M1 and M2 bare, $\mathrm{Cu} 1$ bare and 


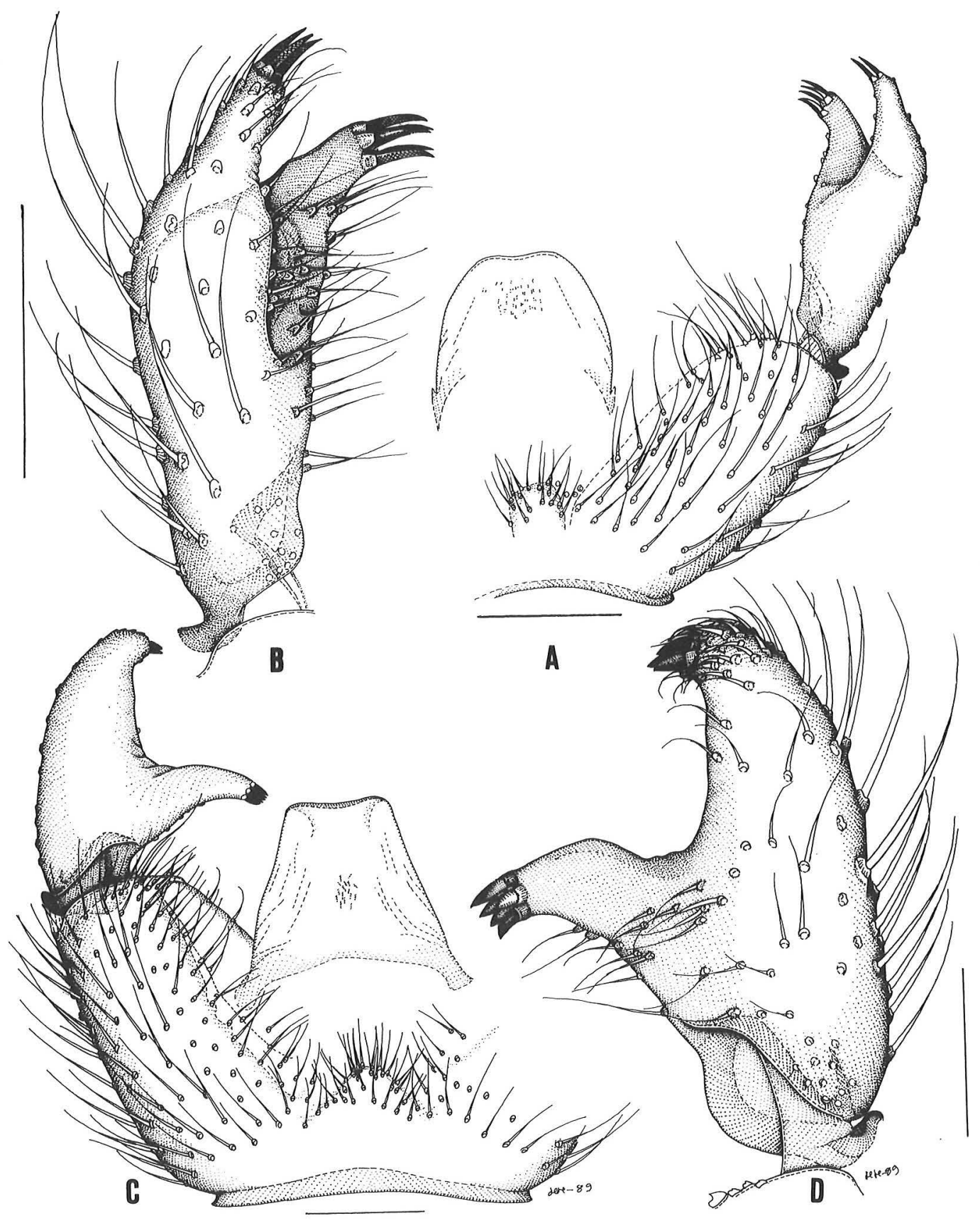

Fig. 24. Part of hypopygium ( $A$ and $C$ ) and gonostylus (B and D), ventral view. - A and B: Prosciara biceps sp. n. (holotype). - C and D: P. duplex sp. n. (holotype). Scale $0.10 \mathrm{~mm}$. 


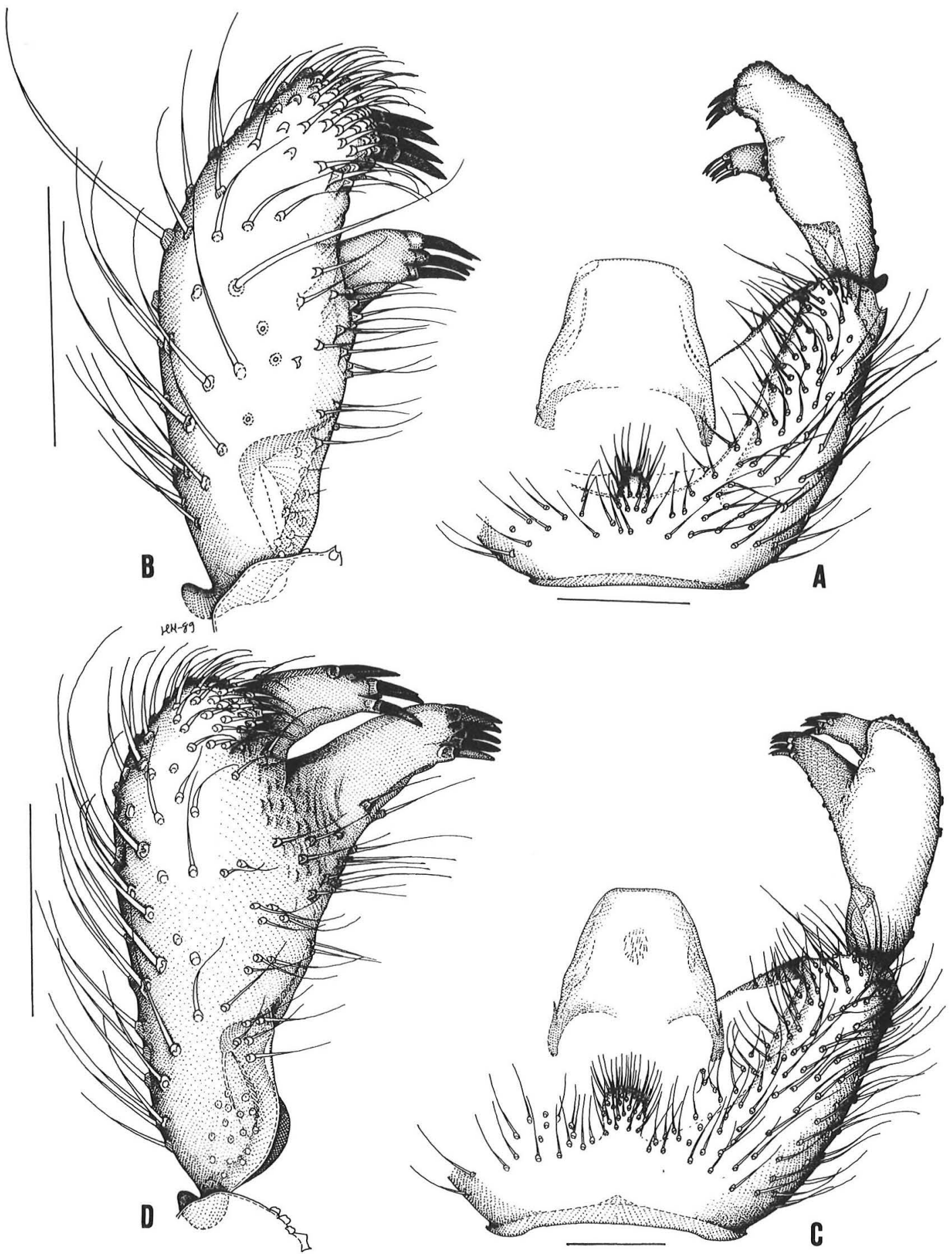

Fig. 25. Part of hypopygium ( $A$ and $C$ ) and gonostylus (B and D), ventral view. - A and B: Prosciara triloba sp. $n$. (holotype). - C and D: P. gemellata sp. n. (holotype). Scale $0.10 \mathrm{~mm}$. 
Cu2 bare. - Legs: Femur 1/metatarsus $10.85-$ 0.90. Apex of tibia 1 with a comb of 7-10 setae. Length of spur/width of tibia 1 1.90-2.10. Tibia 1 with 3-4 dorsal, 1-3 ventral, 0-1 prolateral and 1-3 retrolateral spinose setae. Tibia 2 with $2-4$ dorsal spinose setae. - Abdomen: Sternite 8 with 16 setae. - Hypopygium: Fig. 25. Sternite 10 with 1-2 setae on each half.

\section{Discussion}

$P$. triloba is similar to $P$. gemellata. For distinguishing characters, see under the latter. One specimen of $P$. triloba studied is distinctly larger than the others (length of wing $3.5 \mathrm{~mm}$ versus 2.8-2.9 mm) but except for size we cannot find any characters which would distinguish this specimen from the others.

Acknowledgements. We thank Dr. P. T. Lehtinen (Turku), Dr. J. K. Liebherr (Ithaca) and Dr. J. R. Vockeroth (Ottawa) for part of the material studied.

\section{References}

Antonova, E.B. (Антонова, Е. Б.) 1977: [Review of the species of the genus Phytosciara Frey (Diptera, Sciaridae) in the Palearctic fauna.] (in Russian). Trudy Biologe-Potshvennoge Inst. 46:109-114.

Freeman, P. 1983: Sciarid flies - Diptera, Sciaridae. Handbooks for the identification of British insects 9(6): 1-68. R Entomol. Soc. London, London.

Frey, R. 1942: Entwurf einer neuen Klassifikation der Mückenfamilie Sciaridae. - Notulae Entomol. 22:544.

- 1948: Entwurf einer neuen Klassifikation der Mückenfamilie Sciaridae. II. Die nordeuropeischen Arten. - Notulae Entomol. 27:33-92.

Gerbachevskaja-Pavluchenko, A. A. 1986: Family Sciaridae. - In: Soós, Á. \& Papp, L. (eds.), Catalogue of Palaearctic Diptera 4:11-72. Elsevier, Amsterdam.

Hennig, W. 1966: Phylogenetic systematics. - Univ. of Illinois Press, URBANA, Chicago-London. 263 pp.

\section{Note added in proof}

After this paper was completed we received a paper "Two new Indian species of Phytosciara Frey (Sciaridae: Diptera)" by S. Alam, P. K. Chauduri \& S. K. Dasgupta (Entomon 14:109$115,1989)$. Both of the described species belong to Prosciara in the present sense and were described from material from Darjeeling and Silliguri.
Krivosheina, N. P. \& Morig, W. К. (Кривошейна, Н. П. \& Мориг, В. К.) 1986: Sciaridae (Diptera) of the European part of the USSR. (In Russian) - Entomol. Obozr. 65:153-163.

Lackschewitz, P. 1934: Über die Sciariden (Dipt.) des Ostbaltikum. - Korrespondenzblatt des Naturforschervereins zu Riga 61:151-155.

Lengersdorf, F. 1924: Über die Winnertz'sche Sciaridensammlung in Bonn. - Wiener Entomol. Zeitung. 41:612.

- 1925: Beitrag zur Kenntnis der Gattung Sciara Mgn. - Vorhandl. Naturhist. Ver. Pruss. Rheinl. Westf. 81:203-214.

- 1929: Die Revision der Sciaridensammlung des Pfarrers Dr. W. Grzegorzek. — Bull. Acad. Pol. Sci. Lettr., Cl. Sci. Mat. Nat., Sér. B. Sci. Nat. (Zool.) 1928:105-112.

- 1930: Lycoriidae (Sciaridae). - In: Lindner, E. (ed.), Die Fliegen der palaearktischen Region II(7):1-71.

Mohrig, W., Krivosheina, N. \& Mamaev, B. 1982: Beiträge zur Kenntnis der Trauermücken (Diptera, Sciaridae) der Sowjetunion. Teil II: Neue Sciariden aus SüdPrimorje. —Zool. Jahrb. Syst. 109:170-187.

- 1985: Beiträge zur Kenntnis der Trauermücken (Diptera, Sciaridae) der Sowjetunion. Teil VII: Neue Arten aus Amur-Gebiet. — Zool. Jahrb. Syst. 112:249-260.

Steffan, W. A. 1966: A generic revision of the family Sciaridae (Diptera) of America north of Mexico. Univ. California Publ. Entomol. 44:1-77.

- 1969: Insects of Micronesia, Diptera: Sciaridae. Bernice P. Bishop Mus., Insects of Micronesia 12(7): 669-732.

- 1972: Oriental Sciaridae (Diptera) I. Redescription and review of species described by Edwards and Brunetti. - Pacific Insects 14:589-605.

- 1973: Notes on Hawaiian Sciaridae (Diptera) and descriptions of two new species. - Pacific Insects 15:353-361.

- 1981: Sciaridae. - In: McAlpine, J. F. et al. (eds.), Manual of Nearctic Diptera 1:247-255. Ottawa.

Tuomikoski, R. 1960: Zur Kenntnis der Sciariden (Dipt.) Finnlands. - Ann. Zool. Soc. 'Vanamo' 21(4):1-164.

Wiley, E. O. 1981: Phylogenetics. The theory and practice of phylogenetic systematics. - John Wiley \& Sons, New York. 439 pp.

Winnertz, J. 1867: Beitrag zu einer Monographie der Sciarinen. - Wien. 187 pp.

$P$. insignituberosa, comb. n., was described in Phytosciara (Dolichosciara). It resembles $P$. pentadactyla but the megasetae on the dorsal lobe of the gonostylus are four, not five, and considerably stronger than in $P$. pentadactyla.

$P$. bituberosa was described in Phytosciara (Prosciara). It resembles $P$. triloba but is distinguished e.g. by having the tegmen "subconical" instead of nearly parallel-sided and apically truncate. 